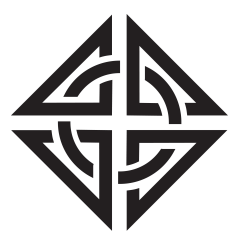

SCIENTIA

I RA N I C A
Sharif University of Technology

Scientia Iranica

Transactions C: Chemistry and Chemical Engineering

http://scientiairanica.sharif.edu

\title{
Introducing a new co-polymeric adsorbent with fast sorption rate and high sorption capacity for removing the heavy metal ions: A thermodynamic and kinetic study
}

\author{
R. Abdolahi, V. Goodarzi, and M.H. Baghersad* \\ Applied Biotechnology Research Center, Baqiyatallah University of Medical Sciences, Tehran, Iran. \\ Received 11 September 2019; received in revised form 2 February 2020; accepted 12 July 2020
}

\author{
KEYWORDS \\ Polymeric adsorbent; \\ Heavy metal ions; \\ Isotherm; \\ Kinetic; \\ Thermodynamics;
}

\begin{abstract}
Heavy metal ions received special attention as the most hazardous contaminants of water sources. In this study, a novel polymeric adsorbent based on 2-hydroxyethyl methacrylate (HEMA), Acrylic Acid (AA), and 1,4-butanediol dimethacrylate (BDDMA) was successfully synthesized and its efficiency for removing the selected heavy metal ions $\left(\mathrm{Pb}^{2+}\right.$ and $\left.\mathrm{Cd}^{2+}\right)$ was investigated. The role of significant parameters such as $\mathrm{pH}$, contact time, adsorbent dose, metal ions concentration, and temperature in removing harmful metal ions were logically studied. The results of the present study showed that there is a direct relation between the parameters such as the amount of $\mathrm{pH}$, the contact time, the polymer adsorbent dosage, and the adsorption of metal ions. This is while the increase of the metal ion concentrations had no significant effect on the adsorption of metal ions which were fixed up to $15 \mathrm{mg} / \mathrm{L}$. The adsorption isotherm process for the new polymeric adsorbent was studied by using selected models, also the maximum values of the adsorption capacities of the introduced adsorbent for $\mathrm{Pb}^{2+}$ and $\mathrm{Cd}^{2+}$ ions were determined. The adsorption /desorption cycles of synthesized polymer adsorbent were repeated 15 times. By modeling the adsorption data, the pseudo-second-order kinetic equation could best describe the adsorption kinetics. The results of the intra-particle diffusion studies showed that the adsorption of heavy metal ions might fallow the external diffusion mechanism.
\end{abstract}

(C) 2021 Sharif University of Technology. All rights reserved.

\section{Introduction}

Some sources of the $\mathrm{Cd}^{2+}$ containing contaminant include: jungle burning, volcanos, human activities, industrial wastes, and phosphate fertilizers [1]. Like

\footnotetext{
*. Corresponding author.

E-mail address: reza.ch9044@gmail.com (R. Abdolahi); v.goodarzi@hotmail.com (V. Goodarzi);

Hadibaghersad@bmsu.ac.ir (M.H.Baghersad)
}

doi: $10.24200 /$ sci.2020.54302.3691 most other kinds of the heavy metals, the $\mathrm{Cd}^{2+}$ could cause various disorders of bones and lungs, and it could reduce the bacterial and viral resistance [2]. The $\mathrm{Pd}^{2+}$ is another highly toxic ion, and exposure to this toxic ion could cause a broad range of adverse effects in both children and adults. Some complications following from the presence of this ion include: blood pressure, fertility problems, nervous disorders, muscle and joint pains, and loss of memory in adults [3].

The presence of heavy metals ions in the water sources may endanger the environment and the health of mankind. Therefore, the elimination of heavy metal 
ions from the environment had recently received a great deal of attention as an urgent issue in the field of environmental chemistry [4].

The attraction of heavy metal ions such as $\mathrm{Pb}^{2+}$ and $\mathrm{Cd}^{2+}$ by living organisms results in the serious disorders in their metabolic activities and brings about some undesired and unnormal consequences [5].

The different solutions are employed to prevent the pollution resulting from heavy metal ions exposure some of which include: adsorption, chemical precipitation, coagulation, flocculation, electrodialysis, membrane filtration, and ion exchange [6-10].

However, in most cases the application of these techniques is associated with some disadvantages, some of which include: being costly, dissemination of toxic compounds, and demanding high level of energy and large space [11]. Among all available techniques, a cost-effective method which could have an efficient contribution to remove the toxic metal ions is the application of the low-cost adsorbents [12].

To this and, several inorganic and organic adsorbents could be used of which the following may serve as examples: zeolites, montmorillonite, clay minerals, trivalent and tetravalent metal phosphates, biosorbents, activated carbon, polymer-based adsorbent, and polymer-inorganic hybrid adsorbents. Among these adsorbents, the polymer-based or polymeric adsorbents such as polyaniline (PANI), polyethyleneimine (PEI), polypyrrole (Ppy) and their composites have received considerable attention. The importance of these adsorbents follows from the following factors: their capability and efficiency for adsorbing various heavy metal ions, being easily applied, being easily operated, having appropriate stability and being relatively costeffective [13]. The application of polyamidoaminecyclodextrin for adsorbing heavy metal ions was introduced by $\mathrm{Li}$ and coworkers. The different factors that affect the performance of polymeric adsorbents were the subject of some studies the results of which show that the polyamidoamine-cyclodextrin has an high potential for adsorbing the harmful ions [14]. A pyromellitic acid dianhydride/ N-(3-(trimethoxysilyl) propyl ethylene diamine (PMDA/TMSPEDA) hybrid polymeric nanocomposite was synthesized and applied by Alsohaimi and coworkers. They showed that the performance of this new adsorbent in terms of heavy metal ions adsorption was acceptable and satisfying. [15]. Also, the polyampholyte hydrogel which has the capability of sorption of heavy metal ions was synthesized by Zhou and coworkers. This adsorbent was tested and its capacity for adsorbing the selected heavy metal ions was evaluated [16].

A review of the field literature reveals a scarcity of research regarding the issue under consideration and that there are only very few cases in which the issue of providing and applying the new polymeric adsorbents for removing heavy metal ions were investigated. Therefore $[17,18]$, to continue our previous researches $[17,18]$ conducted in this field, the aim of which was to develop the new adsorbent, in the present study a new polymeric adsorbent with the base of the acrylate family was proposed. The results of the FTIR analysis showed that the 2-hydroxyethyl methacrylate - acrylic acid (AA) - 1,4-butanediol dimethacrylate (HEMA-AA-BDDMA) polymer was successfully synthesized. The activities of the synthesized adsorbent to remove the $\mathrm{Pb}^{2+}$ and $\mathrm{Cd}^{2+}$ ions were investigated under different conditions. Furthermore, the effect of different parameters such as $\mathrm{pH}$, metal ion concentrations, temperature, contact time, the mass of polymer, and the stirring speed was also examined. Finally, the isothermal process and kinetic studies on new adsorbent were studied with several proposed models.

\section{Experimental}

\subsection{General}

The ultra pure grade reagents used in this study include; 2-hydroxyethyl methacrylate, 1,4-butanediol dimethacrylate, acrylic acid, AIBN, THF, $\mathrm{Cd}\left(\mathrm{NO}_{3}\right)_{2}$, $\mathrm{Pb}\left(\mathrm{NO}_{3}\right)_{2}$ and organic materials include; $\mathrm{HCl}$ and $\mathrm{NaOH}$ were purchased from Merck with ultra-pure grade, Co (Germany). These materials were used without further purification. An aqueous solution of the metal salt prepared with distilled water. Stock solutions of $\mathrm{Pb}^{2+}(500 \mathrm{mg} / \mathrm{L})$ and $\mathrm{Cd}^{2+}(500 \mathrm{mg} / \mathrm{L})$ were prepared by dissolving $0.0799 \mathrm{~g}$ of $\mathrm{Pb}\left(\mathrm{NO}_{3}\right)_{2}$ and $0.1374 \mathrm{~g}$ of $\mathrm{Cd}\left(\mathrm{NO}_{3}\right)_{2} \cdot 4 \mathrm{H}_{2} \mathrm{O}$ in deionized water, respectively, and also these solutions were diluted for preparing other solutions with different concentrations.

\subsection{Measurements}

Atomic absorption spectrometry (AAS- analytical jenanov AA400, fitted with lead and cadmium hollow cathode lamp, Germany) was used to detect the heavy metal ions. The related wavelengths for lead and cadmium in this spectroscopy were, respectively, 283.3 and 228.8. A digital pH meter (Metrohm 827, Switzerland) was used to measure the $\mathrm{pH}$ and the $\mathrm{pH}$ results for each ion was adjusted with $0.1 \mathrm{NaOH}$ or $\mathrm{HCl}$ standard solutions purchased from Merck. A horizontal bench shaker was used to ensure proper exposure (Heidolph PROMAX 2020, Germany). The chemical functional groups was identified by Fourier transform infrared spectroscopy (FT-IR- Nexus-670Thermo Nicolet, USA). To study the crystal structure and morphology of the particles, X-ray diffraction (X pert Philips-Netherland) and scanning electron microscopy (SEM- MIRA3 TESCAN, Czech Republic) were utilized. Thermogravimetric Analysis (TGA) of the polymer was performed with a LENSES STA 
PT-1000 calorimeter (Germany) at a heating rate of $10^{\circ} \mathrm{C} / \mathrm{min}$ up to $600^{\circ} \mathrm{C}$ under $\mathrm{N}_{2}$ atmosphere.

\subsection{Preparation of polymeric adsorbent}

To synthesize the adsorbent polymer, $1 \mathrm{~g}(0.014 \mathrm{~mol})$ acrylic acid and $1.822 \mathrm{~g}(0.014 \mathrm{~mol})$ 2-hydroxyethyl methacrylate with $1.584 \mathrm{~g}$ (0.007 mol) 1,4-butanediol dimethacrylate as a crosslinker agent at a molar ratio of 1: 1: 0.5 in THF as solvent was degassed in the presence of Ar for $20 \mathrm{~min}$ and then AIBN as a primer added to the solvent. The obtained mixture was then refluxed for 24 hours at the Ar atmosphere. Following the polymerization process, network polymer was formed in the solution, then the polymer collected from the solution by filtration was washed several times with THF and then dried for 24 hours in a vacuum oven at $50^{\circ} \mathrm{C}$. Schematic of the synthesis process is shown in Scheme 1.

The swelling index $(x)$ of the synthesized polymer was investigated and calculated using Eq. (1). Therefore, $0.5 \mathrm{~g}$ of HEMA-AA-BDDMA polymer was completely dried and dispersed in deionized water. It was then dried again after a certain time and the swollen polymer was weighed. The results showed that the adsorption of water can be considered as a property of the polymer texture and functional groups, which are responsible for improvement or depreciation of hydrophilicity.

$$
x(\%)=\frac{M_{s}-M_{d}}{M_{s}} \times 100,
$$

where $M_{s}$ and $M_{d}$ are the mass of swollen and dry polymer, respectively.

\subsection{Adsorption investigations}

Adsorption experiments were conducted with dispersing $10 \mathrm{mg}$ of synthesized polymer in $10 \mathrm{ml}$ of $\mathrm{Cd}^{2+}$ and $\mathrm{Pb}^{2+}$ solutions in a $50 \mathrm{ml}$ beaker. The standard solutions were diluted and prepared for experiment.The system was then stirred $200 \mathrm{rpm}$ at ambient temperature. When the adsorption process was completed, the solutions were filtered and the concentration of the metal ions was measured by atomic absorption spectrometry. The obtained results were used to calculate the removal percent of metal ions by Eq. (2):

$$
\text { heavy metal ions removal }(\%)=\left(\frac{C_{0}-C_{e}}{C_{0}}\right) \times 100 \text {, }
$$

where $C_{0}$ and $C_{e}$ are initial and equilibrium concentrations of metal ions, respectively.

\subsection{Key adsorption parameters investigation}

To investigate the effect of $\mathrm{pH}$ on the adsorption of $\mathrm{Pb}^{2+}$ and $\mathrm{Cd}^{2+}$, the concentration of which was about $10 \mathrm{mg} / \mathrm{L}, 10 \mathrm{ml}$ of solutions containing metal ions was used. In this study, the $\mathrm{pH}$ was adjusted to the desired value with $\mathrm{HCl} 0.1 \mathrm{~N}$ or $\mathrm{NaOH} 0.1 \mathrm{~N}$ in the range of $2-6$ and the solutions were stirred for $90 \mathrm{~min}$ after adding a certain amount of HEMA-AA-BDDMA polymer. The solutions were filtered through Whatman no. 42 filter paper when the adsorption process was finished and supernatant solutions were measured using an atomic absorption spectrometry. The results were the average value obtained upon repeating the experiment four times.

The adsorption experiments were performed in the range of 10-180 min for the initial concentration of toxic metal ions $(10 \mathrm{mg} / \mathrm{L})$ at $\mathrm{pH}$. The optimum amount of the added polymer to the solutions was $10 \mathrm{mg}$ in a $50 \mathrm{ml}$ beaker. The solutions under consideration were stirred at room temperature. A procedure similar to previous section was used to measure the adsorbed metal ions.

Different amount of adsorbent was used in this experiment for $10 \mathrm{ml}$ of metal ion solutions with a concentration of $10 \mathrm{mg} / \mathrm{L}$ in $\mathrm{pH}=6$ for $90 \mathrm{~min}$ at room temperature. The samples were filtered and analyzed by atomic absorption spectrometry.

The effect of the initial concentration of metal ions on the adsorption behavior of HEMA-AA-BDDMA polymer was also investigated. Various concentrations of metal ion solutions with constant volume $(10 \mathrm{ml})$ were prepared $(5-45 \mathrm{mg} / \mathrm{L})$ and the adsorption behavior of HEMA-AA-BDDMA polymer $(10 \mathrm{mg})$ in $\mathrm{pH}=6$ was measured by atomic absorption spectrometer after stirring for $90 \mathrm{~min}$ at room temperature and filtration.

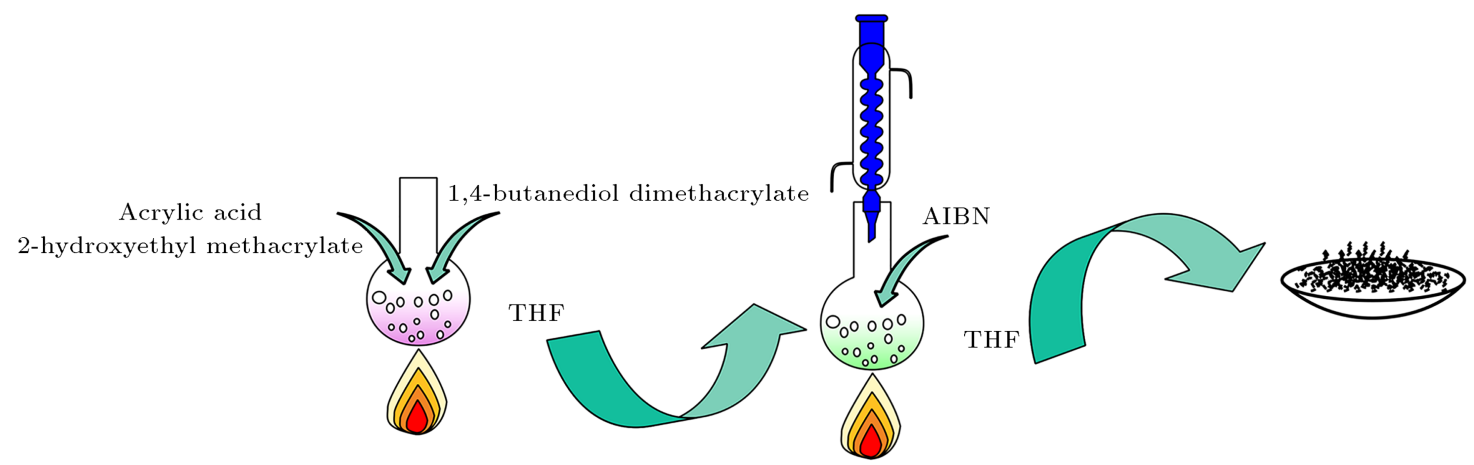

Scheme 1. Synthesis process of copolymer. 
To study the effect of stirring speed on the adsorption, $10 \mathrm{ml}$ of metal ion solutions with a concentration of $10 \mathrm{mg} / \mathrm{L}$ with a certain amount of HEMA-AABDDMA polymer was stirred at $\mathrm{pH}=6$ at room temperature with various speeds of stirring (100-300 rpm) for $90 \mathrm{~min}$. The obtained samples were analyzed according to the procedure described in previous sections and by using atomic absorption spectrometry.

To investigate the effect of the temperature on the adsorption behavior, the solutions with certain concentrations and volume at the temperature range of $10-40^{\circ} \mathrm{C}$ were considered. It should be noticed that throughout the temperature optimization, 10 $\mathrm{mg}$ of HEMA-AA-BDDMA polymer at $\mathrm{pH}=6$ was used for $90 \mathrm{~min}$ as an optimum time of adsorption. The obtained samples were analyzed with AAS after filtration.

\subsection{Recycling and frequent application of the adsorbent}

The desorption of metal ions from the surface of HEMA-AA-BDDMA polymer was performed using a $0.2 \mathrm{M} \mathrm{HCl}$ solution. $\mathrm{HCl}$ solution containing polymer particles was stirred for $30 \mathrm{~min}$ to reach equilibrium and the samples were analyzed using AAS. The desorption ratio (D) of metal ions was calculated using Eq. (3):

$$
D(\%)=\frac{C_{d} V_{d}}{\left(C_{0}-C_{e}\right) V} \times 100,
$$

where $V$ is the solution volume, $C_{d}$ is the concentration of metal ions in the desorbed solution based on $\mathrm{mg} / \mathrm{L}$, and $V_{d}$ is the volume of desorbed solutions. The collected polymer from the desorption process was washed with deionized water and dried for further use. This process was repeated 15 times.

\subsection{Equilibrium isotherms and kinetic studies} Isotherms and kinetic studies were investigated in the presence of $0.01 \mathrm{~g}$ HEMA-AA-BDDMA polymer. Metal ion solutions with various concentrations were prepared and the $\mathrm{pH}$ was adjusted to 6 . After shaking the solution for $90 \mathrm{~min}$ in the presence of polymer, the equilibrium concentration of the metal ions was measured with AAS. Eq. (4) was used to measure the adsorbed metal ion $\left(q_{e}\right)$ by HEMA-AA-BDDMA polymer:

$$
q_{e}=\frac{\left(C_{0}-C_{e}\right) V}{m},
$$

where $q_{e}$ is the adsorbed amount of metal ions per unit weight of $\mathrm{mg} / \mathrm{g}, V$ is the solution volume $(L)$, and $m$ is the mass of the adsorbent. To investigate the kinetics of the adsorption process, the samples were isolated according to the aforementioned procedure and analyzed with AAS. The amounts of the adsorbed metal ions were calculated in the times $t$ and $q_{t}$ using Eq. (5):

$$
q_{t}=\frac{\left(C_{0}-C_{t}\right) V}{m},
$$

where $C_{t}$ is the concentration of metal ions in the solution after the above-mentioned time.

\section{Results and discussion}

\subsection{Synthesis and characterization of polymeric adsorbent}

The polymeric adsorbent was synthesized using radical polymerization method. In the first step, two radicals are created from the AIBN. In the second step, radicals are transferred from the initiator molecules to the carbon-carbon double bonds of HEMA, AA, and BDDMA. Because BDDMA has two carbon-carbon double bonds, two crosslinks between polymer chains could be formed. The structure of the targeted copolymer is shown schematically in Scheme 2. As can be observed from this figure, the synthesized adsorbent has so many active ion-exchange sites that can be generated to remove the heavy metal ions from aqueous solution. The microstructures of polymeric adsorbent were investigated by SEM images and are shown at two different magnifications in Figure 1(a) and (b). The monodispersity and spherical morphology of the particles has been clearly shown in these figures; the diameters of particles are about 100 nanometers. The XRD patterns of the prepared polymer are shown in Figure 1(c). There was only a moderate peak in $2 \theta=20$, which is attributed to the amorphous nature of the polymer. The diffusion of water molecules and metal ions from amorphous regions was very easier than that of crystalline structures. This is an important principle of the polymeric adsorbent.

The swelling behavior of the polymeric adsorbent was studied and the obtained results were shown in Figure 1(d). These results showed that the values of the swelling index of the synthesized polymer were at required levels to ensure removal of heavy metal ions.

The characteristic functional groups of the synthesized polymer and their ability to attract the metal ions were examined by FTIR analysis, the result of which is presented in Figure 2(a). In this figure, the FTIR spectrums of pure adsorbent, adsorbent- $\mathrm{Pb}^{+2}$ and adsorbent- $\mathrm{Cd}^{+2}$ are shown. From the spectrum of the pure polymer it can be seen that some remarkable peaks such as stretching bands of $\mathrm{C}=\mathrm{O}\left(1635 \mathrm{~cm}^{-1}\right)$ are relating to carbonyls of esters groups, aliphatic C$\mathrm{H}\left(2850-3000 \mathrm{~cm}^{-1}\right)$, and O-H $\left(3400-3600 \mathrm{~cm}^{-1}\right)$. The methyl groups showed a weak band at $1380 \mathrm{~cm}^{-1}$ and a medium band at $1260 \mathrm{~cm}^{-1}$. By comparing these bonds, it is revealed that the presence of metal ions affected the mentioned chemical bonds. To clarify 


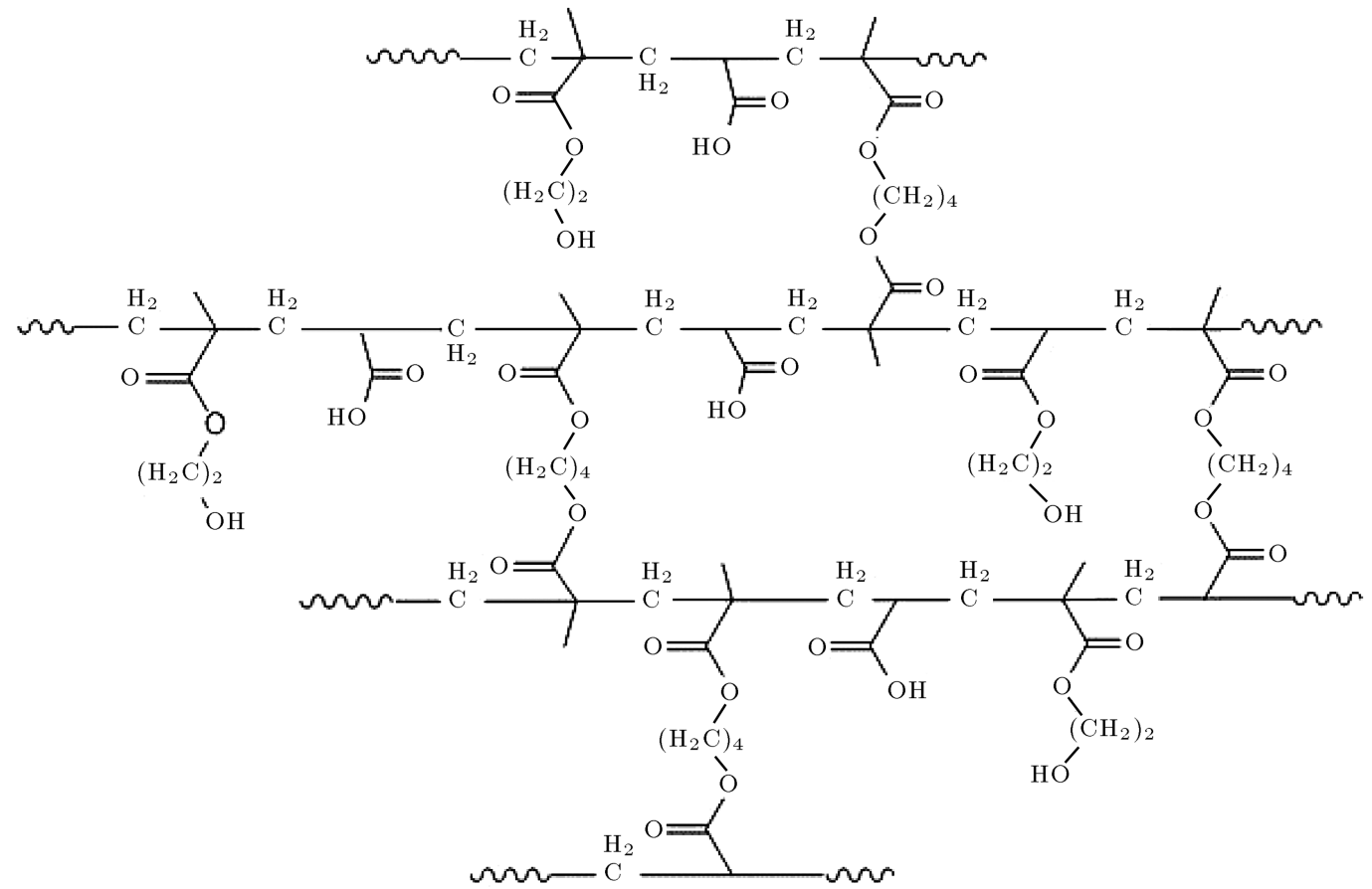

Scheme 2. Structure of synthesized polymer.

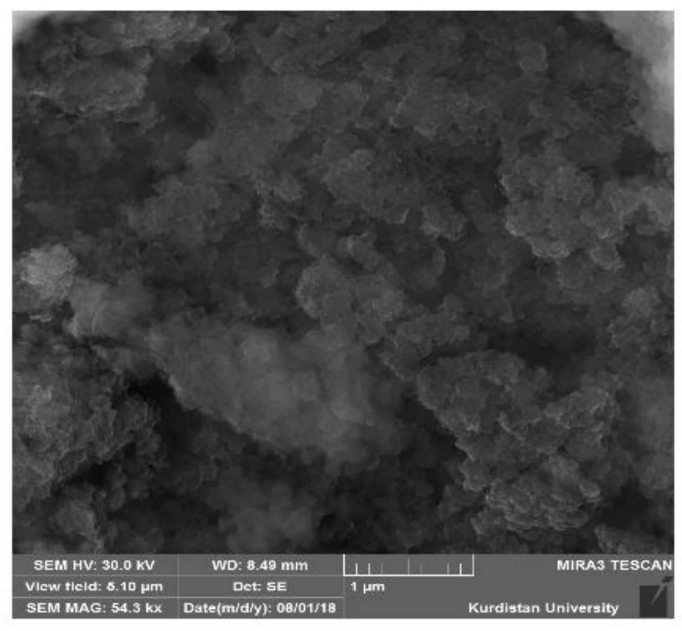

(a)

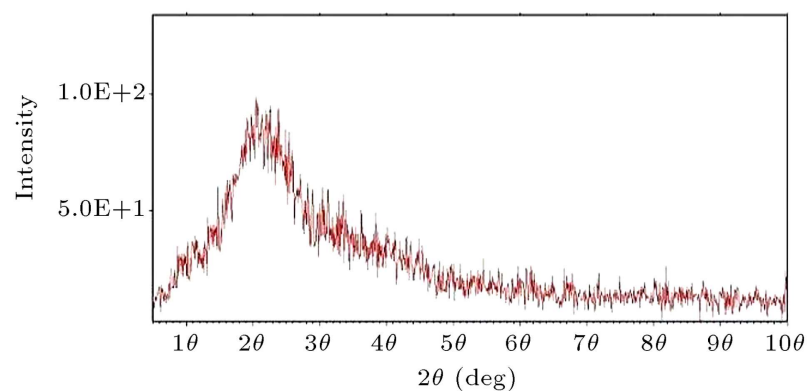

(c)

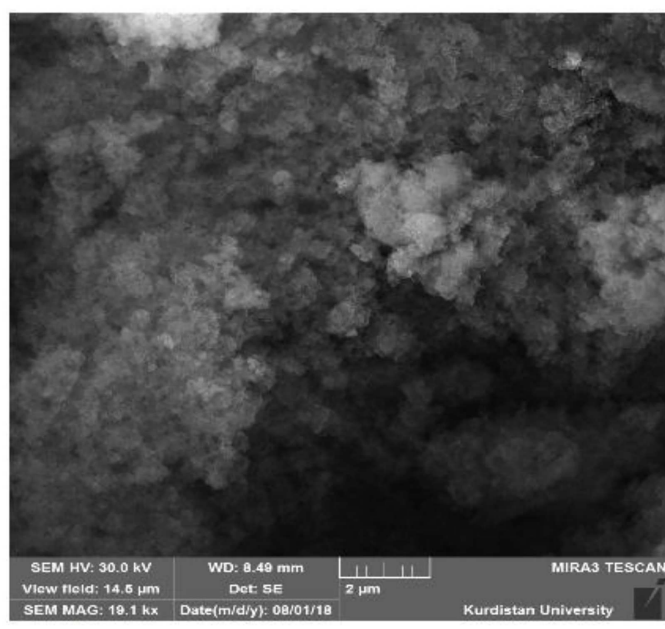

(b)

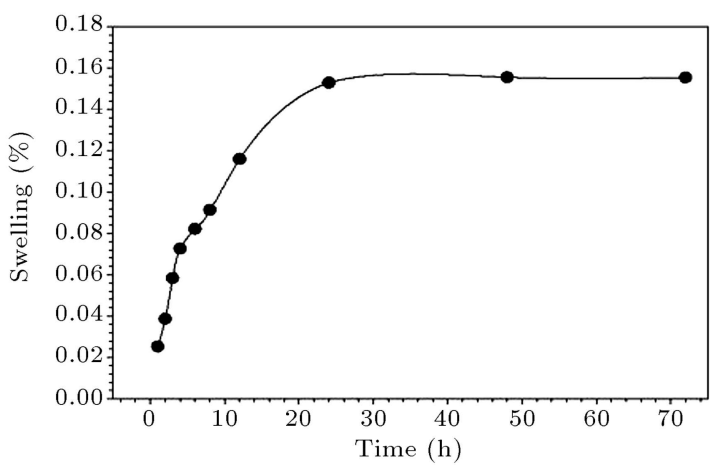

(d)

Figure 1. SEM images of polymer: (a) Scale $=1 \mu \mathrm{m}$, (b) scale $=2 \mu \mathrm{m}$, (c) XRD patterns of the synthesized polymers, and (d) Swelling index of the polymer. 


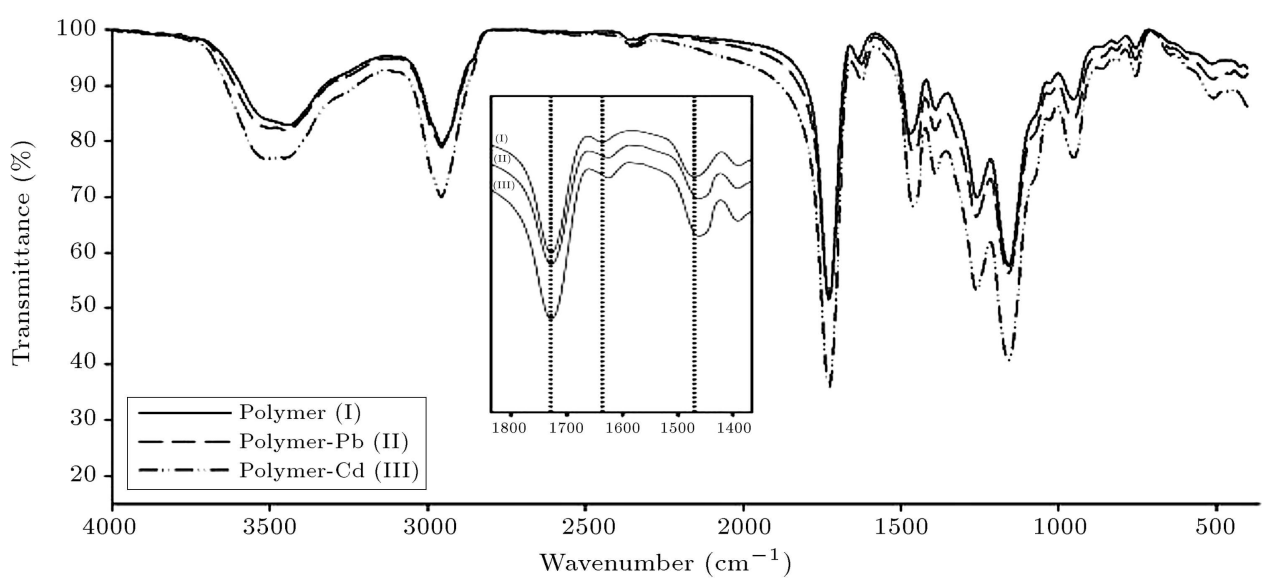

(a)

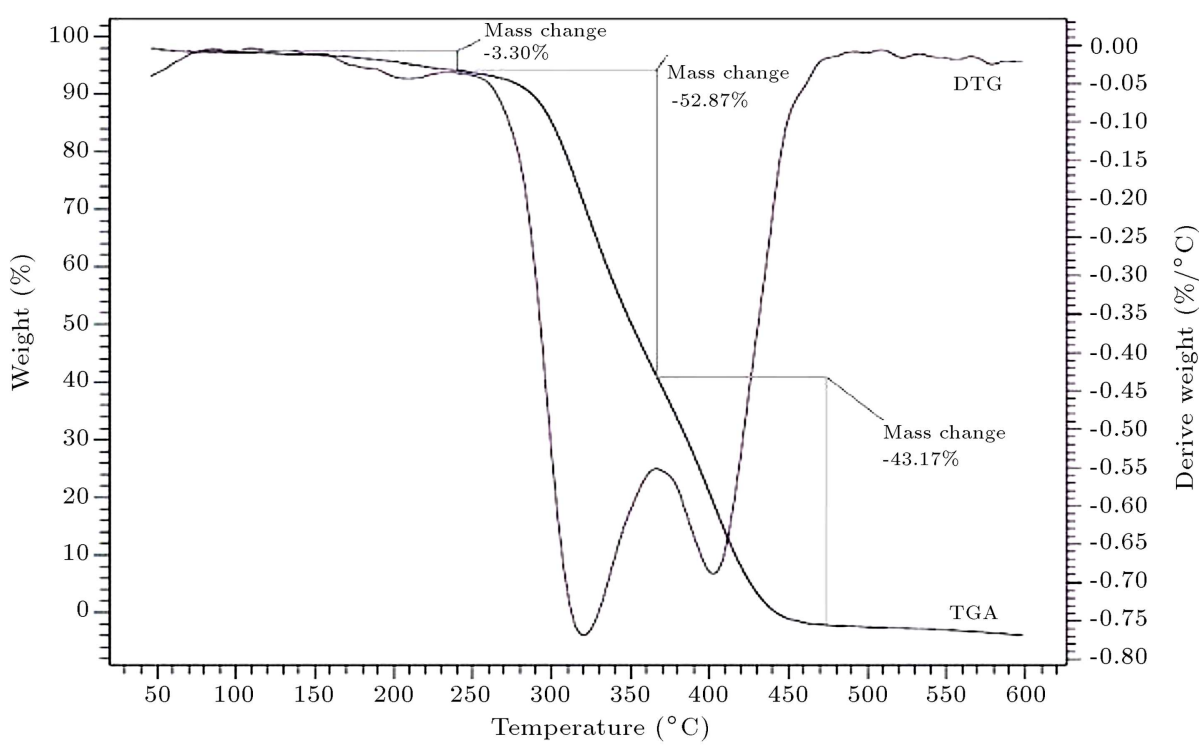

(b)

Figure 2. (a) FT-IR spectra of polymer before and after complexation with $\mathrm{Pb}(\mathrm{II}$ ) and $\mathrm{Cd}(\mathrm{II})$. (b) TGA/differential thermograms of the polymers.

the reason, the FTIR spectral region between 1380 to $2200 \mathrm{~cm}^{-1}$ was zoomed. It can be seen from this figure that after adsorption of metal ions onto the surface of the adsorbent, the peaks located at 1635 $\mathrm{cm}^{-1}$ and $1473 \mathrm{~cm}^{-1}$ were sharpened and shifted to $1625 \mathrm{~cm}^{-1}$ and $1465 \mathrm{~cm}^{-1}$, respectively, which clearly indicates the strong bonds between polymer and metal ions [19].

The TGA and DTG thermo-grams for synthesized polymer can be seen in Figure 2(b). From this figure it can be found that the samples exhibited relatively a high degradation temperature and they had various peaks each of which represented a specific kind of structural decomposition. As results showed, regarding the polymer, the initial weight loss at a temperature of $150^{\circ} \mathrm{C}$ relates to the loss of moisture of the polymer. The second weight loss at the temperature of $250^{\circ} \mathrm{C}$ could be attributed to the formation of acid anhydride from the carboxyl groups with a loss of water. The last step represented the degradation of crosslinking agents.

\subsection{Investigation on effect of key parameters on adsorption of $\mathrm{Pb}^{+2}$ and $\mathrm{Cd}^{+2}$ ions}

The most important parameters of adsorption such as $\mathrm{pH}$, contact time, the dosage of adsorbent, concentration of metal ions, temperature and agitation speed were tested the results of which are as follows.

3.2.1. Sorption of $\mathrm{Pb}^{+2}$ and $\mathrm{Cd}^{+2}$ as a function of $\mathrm{pH}$ In the aqueous solution, $\mathrm{pH}$ plays an essential role in the adsorption of heavy metal ions. In this study, the effect of $\mathrm{pH}$ range of 2-6 on the adsorption of heavy metal ions was investigated, because metal ions can form hydroxide compounds at $\mathrm{pH}$ levels higher than 6 [20]. According to FTIR data, the carboxyl groups of the synthesized polymer have weak acid properties 


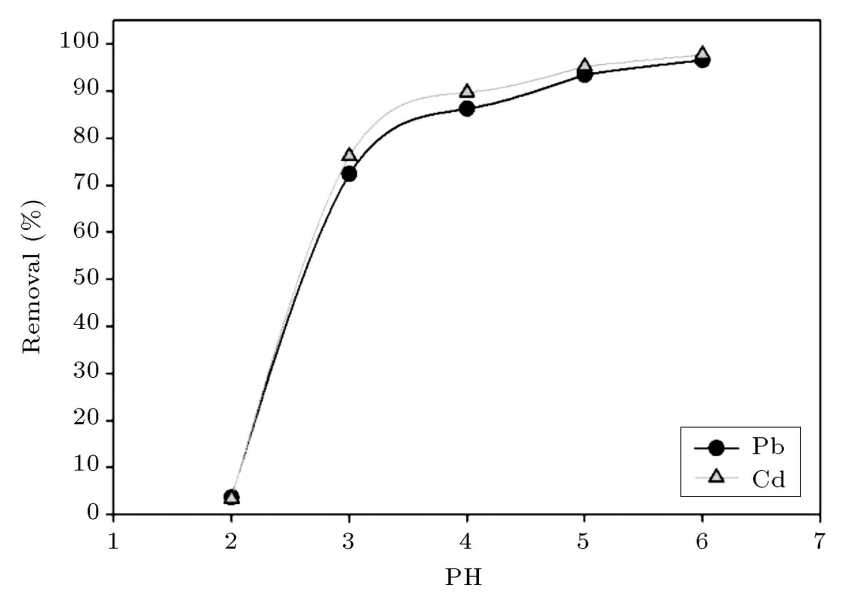

Figure 3. Effect of $\mathrm{pH}$ value on metal ions adsorption onto polymer $\left(\left[\mathrm{Pb}^{2+}\right]=10 \mathrm{mg} / \mathrm{L},\left[\mathrm{Cd}^{2+}\right]=10 \mathrm{mg} / \mathrm{L}\right.$, adsorbent dose $=1 \mathrm{~g} / \mathrm{L}$, contact time $=90 \mathrm{~min}$ ).

and the degree of their protonation at acidic $\mathrm{pH}$ is moderate. The evident result of this property is that there are no strong bonds between functional groups of polymer macromolecules and metal ions. The results of this analysis are presented in Figure 3. As it is clear from the figure, the increase of $\mathrm{pH}$ is an important factor that affects the adsorption of metal ions. As illustrated in this figure, the adsorption level at $\mathrm{pH}$ $=2$ was about 0 , while by increasing $\mathrm{pH}$ to 6 , the adsorption of both metal ions increased and at $\mathrm{pH} 5-6$ a constant state can be easily observed. The highest amount of adsorption for $\mathrm{Pb}^{2+}$ and $\mathrm{Cd}^{2+}$ in $\mathrm{pH} 6$ was $96.59 \%$ and $97.75 \%$, respectively. The reason for the increase in adsorption at $\mathrm{pH}=6$ can be attributed to the decrease in the concentration of hydrogen ions, which reduces the competition of these ions with $\mathrm{pb}^{2+}$ and $\mathrm{cd}^{2+}$ ions to bind to active polymer sites, which allows more adsorption of $\mathrm{pb}^{2+}$ and $\mathrm{cd}^{2+}$ ions by the polymer adsorbent.

\subsubsection{Effect of contact time on adsorption}

Another important factor that affects the adsorption of metal ions onto solid surfaces of adsorbent is contact time. The effect of this factor on the efficiency of adsorbent within a time range between 0 to 180 was studied the results of which are presented in Figure 4. It can be seen from this figure that at the initial moments of contact time, the heavy metal ions were rapidly adsorbed, then the adsorption rate decreased gradually. The adsorption reached the equilibrium in about $60-80$ min. These observations could be explained by the fact that the adsorption values for metal ions increase with increasing the contact time, but the polymer chains aggregate over time and the fraction of accessible sites for metal ions begin to decrease. Consequently, the penetration of metal ions into the polymer active sites will be limited and the adsorption process reaches to the equilibrium condition [21].

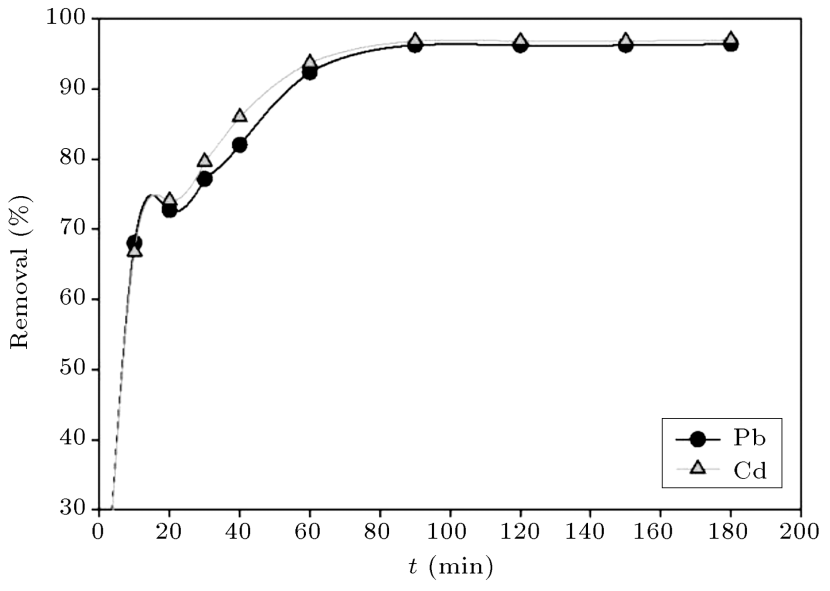

Figure 4. Effect of contact time on the adsorption of heavy metal onto polymer $\left(\left[\mathrm{Pb}^{2+}\right]=10 \mathrm{mg} / \mathrm{L},\left[\mathrm{Cd}^{2+}\right]=\right.$ $10 \mathrm{mg} / \mathrm{L}$, adsorbent dose $=1 \mathrm{~g} / \mathrm{L}, \mathrm{pH}=6)$.

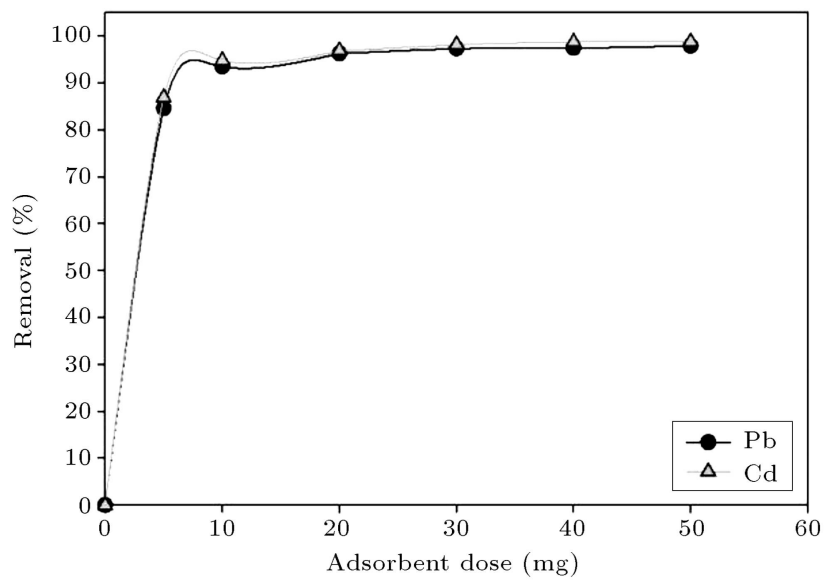

Figure 5. Effect of adsorbent dose on metal ions adsorption by polymer $\left(\left[\mathrm{Pb}^{2+}\right]=10 \mathrm{mg} / \mathrm{L},\left[\mathrm{Cd}^{2+}\right]=10\right.$ $\mathrm{mg} / \mathrm{L}$, contact time $=90 \mathrm{~min}, \mathrm{pH}=6)$.

\subsubsection{Effect of adsorbent dosage}

The amount of polymer adsorbent is an important factor that affects the adsorption of $\mathrm{Pb}^{+2}$ and $\mathrm{Cd}^{+2}$ from aqueous solutions. The results are shown in Figure 5. The results demonstrated that the adsorption performance of the synthesized polymer increased gradually by increasing the amount of polymer. This result was expected because the increase of the concentration of adsorbent provides more surface area, and consequently, more active sites for adsorption of metal ions will be provided [22].

\subsubsection{Effect of metal ion concentration}

The adsorption rate is a function of metal ion concentration and this can be considered as an important factor. The confirmative results of the present study are shown in Figure 6. Generally, these results demonstrated that the increase of metal ion concentration to about $15 \mathrm{mg} / \mathrm{L}$ lead to constant value adsorption and this can be attributed to the saturation of the active 


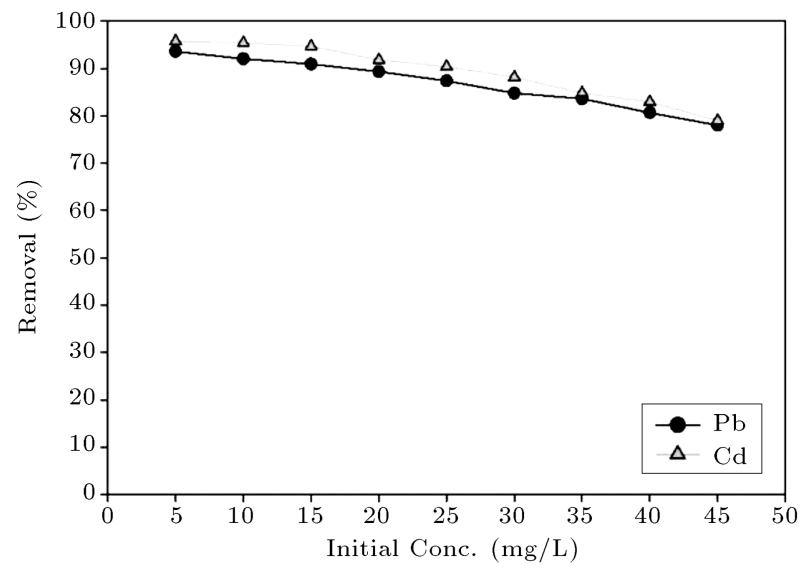

Figure 6. Effect of concentration of metal ion on metal ions adsorption by polymer (adsorbent dose $=1 \mathrm{~g} / \mathrm{L}$, contact time $=90 \mathrm{~min}, \mathrm{pH}=6)$.

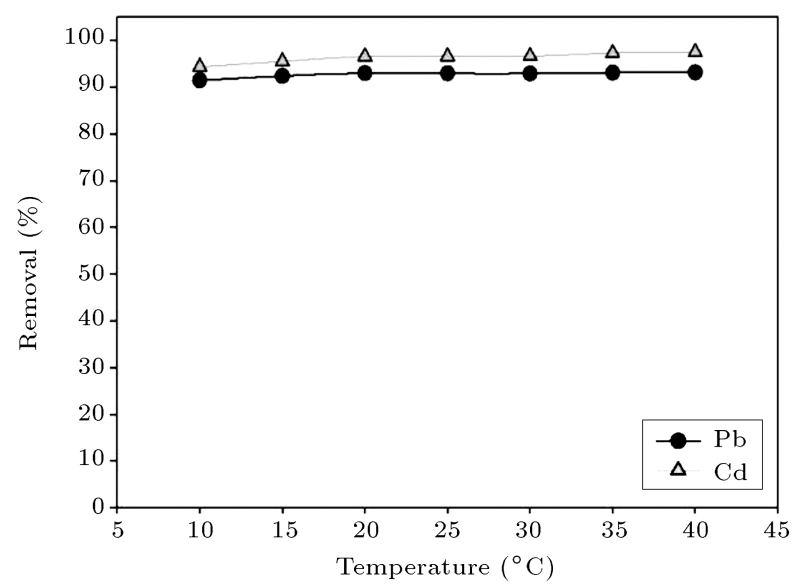

Figure 7. Effect of temperature on metal ions adsorption by polymer $\left(\left[\mathrm{Pb}^{2+}\right]=10 \mathrm{mg} / \mathrm{L},\left[\mathrm{Cd}^{2+}\right]=10 \mathrm{mg} / \mathrm{L}\right.$, adsorbent dose $=1 \mathrm{~g} / \mathrm{L}$, contact time $=90 \mathrm{~min}, \mathrm{pH}=6$ ).

sites of the synthesized polymer in high heavy metal ions concentrations. The networked structures of the polymer, shown in Scheme 2, help us to achieve a better understanding of this inference.

\subsubsection{Effect of temperature on metal ions adsorption} To investigate the effect of temperature on the adsorption process, the solutions with the concentration of $10 \mathrm{mg} / \mathrm{L}$ were prepared in different temperatures $(10-$ $45^{\circ} \mathrm{C}$ ) in $\mathrm{pH} 6$. The obtained results are shown in Figure 7 and these results indicated that the increase of temperature improves the adsorption of heavy metal ions. As the results showed, the absorption process investigated in the present study could be considered as an endothermic process.

\subsubsection{Effect of stirring speed on metal ions adsorption}

The effect of speeds of stirring (100-300 rpm) on heavy metal ions adsorption at constant volume and concentration were studied the results of which are

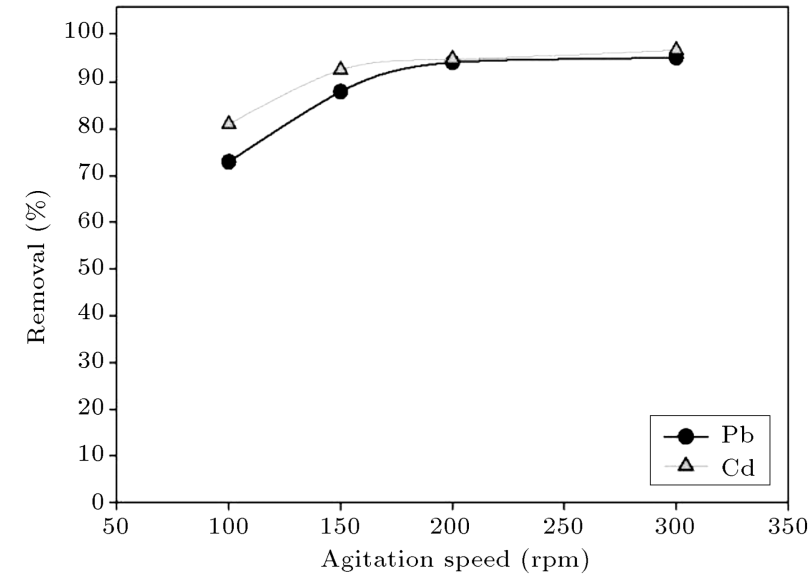

Figure 8. Effect of agitating speed on adsorption of heavy metal ions $\left(\left[\mathrm{Pb}^{2+}\right]=10 \mathrm{mg} / \mathrm{L},\left[\mathrm{Cd}^{2+}\right]=10 \mathrm{mg} / \mathrm{L}\right.$, adsorbent dose $=1 \mathrm{~g} / \mathrm{L}$, contact time $=90 \mathrm{~min}, \mathrm{pH}=6)$.

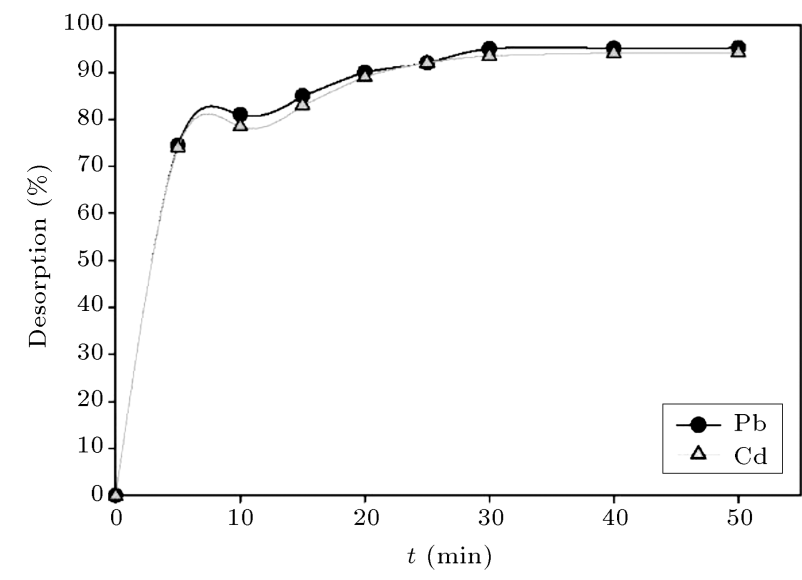

Figure 9. Desorption of metal ions from polymer-metal ions complex by $0.5 \mathrm{M} \mathrm{HCl}$ solution.

presented in Figure 8. As shown in this figure, the increase of stirring speed leads to an increase in heavy metal ions adsorption. The highest rate of adsorption was observed at the speed of about $200 \mathrm{rpm}$ and it was $94.26 \%$ and $94.95 \%$, respectively, for $\mathrm{Pb}^{2+}$ and $\mathrm{Cd}^{2+}$. Thus, it can be claimed that the increase of stirring speed may increase the probability of collisions between adsorbent particles and metal ions and decrease the thickness of barrier film.

\subsection{Desorption and frequent use of newly synthesized adsorbent}

The recyclability is an important factor for many adsorbents and most of them possess high adsorption capacities as well as good desorption properties. The property of desorption is a valuable option from an economic point of view. As seen in Figure 9, the desorption process of desorption of metal ions from the synthesized polymer was a function of time and it reached equilibrium after $30 \mathrm{~min}$ and the desorption ratio of $\mathrm{Pb}^{2+}$ and $\mathrm{Cd}^{2+}$ was, respectively, $95.48 \%$ 


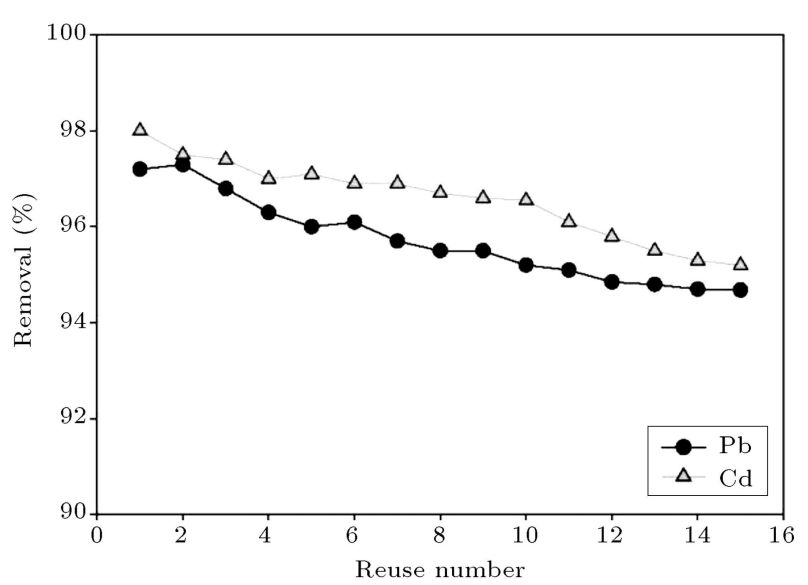

Figure 10. Removal of metal ions after repeated adsorption-desorption operations at $25^{\circ} \mathrm{C}\left(\left[\mathrm{Pb}^{2+}\right]=10\right.$ $\mathrm{mg} / \mathrm{L},\left[\mathrm{Cd}^{2+}\right]=10 \mathrm{mg} / \mathrm{L}$, adsorption time $90 \mathrm{~min}, \mathrm{pH}=$ 6 , adsorbent dose $=1 \mathrm{~g} / \mathrm{L})$.

Table 1. Distribution coefficient, $K_{d}$, of toxic metal ions adsorption by the polymer.

\begin{tabular}{clc}
\hline \multirow{2}{*}{ Polymer } & \multicolumn{2}{c}{$\boldsymbol{K}_{\boldsymbol{d}}(\mathbf{m L} / \mathrm{g}) \times \mathbf{1 0}^{\mathbf{3}}$} \\
\cline { 2 - 3 } & $\mathbf{P b}^{+\mathbf{2}}$ & $\mathbf{C d}^{+\mathbf{2}}$ \\
\hline Synthesized adsorbent & 11.57 & 20.72 \\
\hline
\end{tabular}

and $93.52 \%$. The reusability of the adsorbent with consecutive cycles of adsorption/desorption (15 times) was studied in present work and as shown in Figure 10, there was no significant loss in the adsorption capacity of metal ions during the experiments.

\subsection{Calculation of equilibrium distribution coefficients $\left(K_{d}\right)$ of new adsorbent}

Distribution coefficient $\left(K_{d}\right)$ can be considered as a criterion for the affinity of polymer adsorbent to metal ions following Eq. (6) [23]:

$$
K_{d}=\frac{\text { amount of metal ion in the adsorbent }}{\text { amount of metal ion in solution }} \times \frac{V}{m} \text {, }
$$

where $V$ is the solution volume per unit of $\mathrm{ml}$ and $m$ is the mass of adsorbent per unit of $\mathrm{g}$. The values of $K_{d}$ are listed in Table 1 for $\mathrm{Pb}^{2+}$ and $\mathrm{Cd}^{2+}$. As is evident from this finding, the high values of $K_{d}$ indicated that the concentration of metal ions in the solid phase was high implying that a large amount of adsorbent was present in the solid phase. This indicated a high adsorption capacity of polymer.

\subsection{Modeling of adsorption isothermal data of new adsorbent}

So far, numerous mathematical models have been used to describe the experimental data of adsorbents in isothermal conditions. In this section, several models such as Langmuir [24], Freundlich [25], Temkin and Pyzhev [26], and Dubinin [27] were considered.

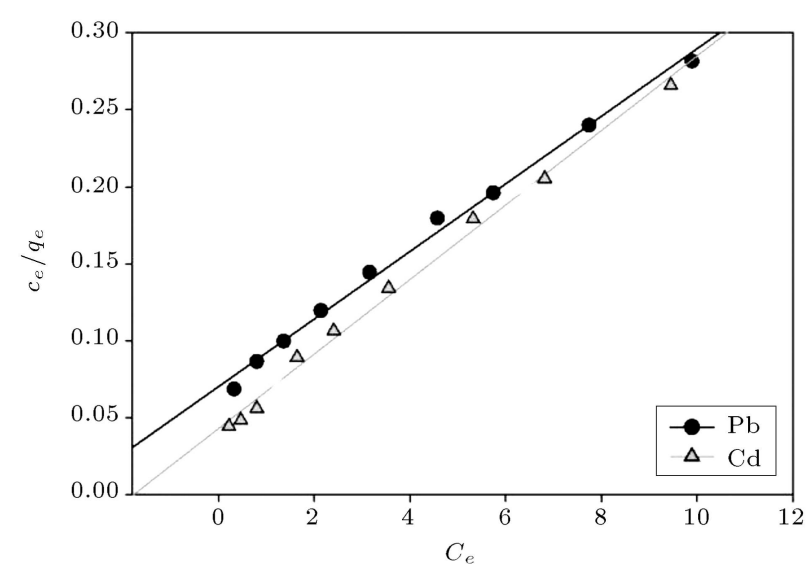

Figure 11. Langmuir isotherms for $\mathrm{Pb}(\mathrm{II})$ and $\mathrm{Cd}(\mathrm{II})$ adsorption onto polymer $(\mathrm{pH}=6$, time $=90 \mathrm{~min}$, resin dose $=1 \mathrm{~g} / \mathrm{L})$.

\subsubsection{Langmuir isotherm}

Langmuir's model is widely used in adsorption processes relating to heavy metal ions. Langmuir's model can be expressed by Eq. (7) [24]:

$$
\frac{C_{e}}{q_{e}}=\frac{1}{K_{L} q_{m}}+\left(\frac{1}{q_{m}}\right) C_{e},
$$

where $C_{e}$ is the equilibrium concentration $(\mathrm{mg} / \mathrm{L}), q_{e}$ is the amount of adsorbed metal ions in the equilibrium state $(\mathrm{mg} / \mathrm{g}), q_{m}$ is the highest capacity of adsorbent $(\mathrm{mg} / \mathrm{g})$, and $K_{L}$ is the Langmuir's constant which is adsorption dependent. The plot of Langmuir adsorption isotherm used in this study was shown in Figure 11. The slope and the ordinate can be, respectively, regarded as $K_{L}$ and $q_{m}$ for $\mathrm{Pb}^{2+}$ and $\mathrm{Cd}^{2+}$. The results of these calculations have been presented in Table 2. It should be noted that the best fit for both cases was Langmuir model. The separation factor of the Langmuir model can be calculated using Eq. (8):

$$
R_{L}=\frac{1}{1+K_{L} C_{0}}
$$

where $C_{0}$ is the initial concentration of metal ion $(\mathrm{mg} / \mathrm{L})$ and $K_{L}$ is the Langmuir constant $(\mathrm{L} / \mathrm{mg})$. Figure 12 shows the results of the separation factor, which is dependent on the concentration of metal ions. The values of $R_{L}$ determine the kind of isotherm which could be reversible $\left(R_{L}=0\right)$, favorable $\left(0<R_{L}<1\right)$, linear $\left(R_{L}=1\right)$, and/or unfavorable $\left(R_{L}>1\right)$. These values were calculated for metal ions and the results showed that they were smaller than 1 , which indicated that the synthesized polymer has favorable adsorption.

\subsubsection{Freundlich isotherm}

Another selected model for adsorption of heavy metal ions was the Freundlich model. This model indicates the heterogeneity in the surface of the adsorbent and can be presented by Eq. (9): 
Table 2. Isotherm parameters for the adsorption of $\mathrm{Pb}(\mathrm{II})$ and $\mathrm{Cd}(\mathrm{II})$ ions onto the polymer.

\begin{tabular}{|c|c|c|c|}
\hline \multirow[b]{2}{*}{ Isotherms } & \multirow[b]{2}{*}{ Parameters } & \multicolumn{2}{|c|}{ Metal ions } \\
\hline & & $\mathbf{P b}^{+2}$ & $\mathrm{Cd}^{+2}$ \\
\hline \multirow[t]{4}{*}{ Langmuir } & $q_{m}(\mathrm{mg} / \mathrm{g})$ & 45.66 & 41.32 \\
\hline & $K_{L}(\mathrm{~L} / \mathrm{mg})$ & 0.312 & 0.563 \\
\hline & $R_{L}$ & 0.391 & 0.262 \\
\hline & $R^{2}$ & 0.9957 & 0.9951 \\
\hline \multirow[t]{3}{*}{ Freundlich } & $K_{F}$ & 12.266 & 15.915 \\
\hline & $\mathrm{N}$ & 2.0995 & 2.6774 \\
\hline & $R^{2}$ & 0.9916 & 0.9837 \\
\hline \multirow[t]{3}{*}{ Temkin } & $b_{T}=R T / B_{T}$ & 0.2397 & 0.2377 \\
\hline & $A_{T}$ & 2.4267 & 4.0624 \\
\hline & $R^{2}$ & 0.9944 & 0.9941 \\
\hline \multirow[t]{4}{*}{ Dubinin } & $X_{m}(\mathrm{~mol} / \mathrm{g})$ & 25.159 & 26.797 \\
\hline & $\beta\left(\mathrm{kJ}^{2} / \mathrm{mol} 2\right)$ & $2 \times 10^{-7}$ & $1 \times 10^{-7}$ \\
\hline & $E(\mathrm{~kJ} / \mathrm{mol})$ & 1.58 & 2.24 \\
\hline & $R^{2}$ & 0.8338 & 0.8967 \\
\hline
\end{tabular}

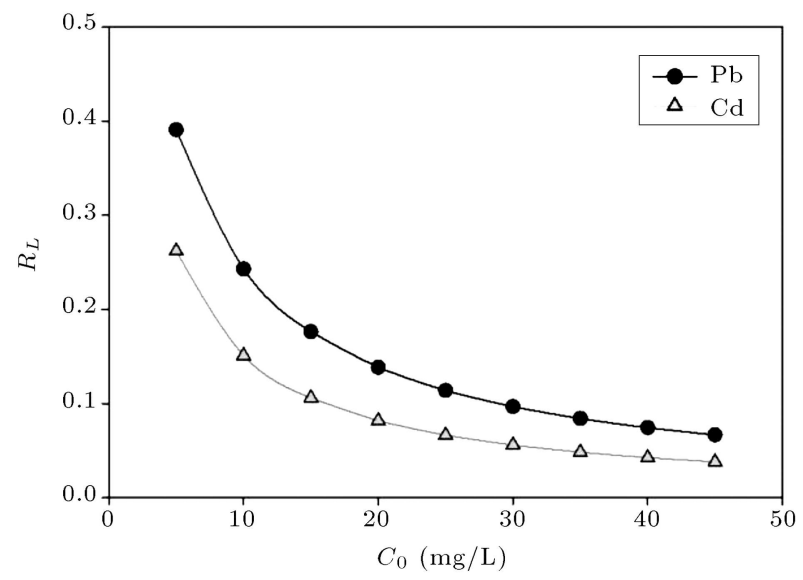

Figure 12. Separation factor (RL) profile for biosorption of $\mathrm{Pb}(\mathrm{II})$ and $\mathrm{Cd}(\mathrm{II})$ as function of concentration of metal ion $(\mathrm{pH}=6$, time $=90 \mathrm{~min}$, resin dose $=1 \mathrm{~g} / \mathrm{L})$.

$$
\log q_{e}=\frac{1}{n} \log C_{e}+\log K_{F}
$$

where $K_{F}$ and $1 / n$ are the experimental constants for the Freundlich equation, which indicate, respectively, the relative capacity of adsorption and adsorption intensity. This model was applied to the experiment the results of which are shown in Figure 13. The Freundlich equation constants can be calculated from the slope and ordinate of this line. The obtained values

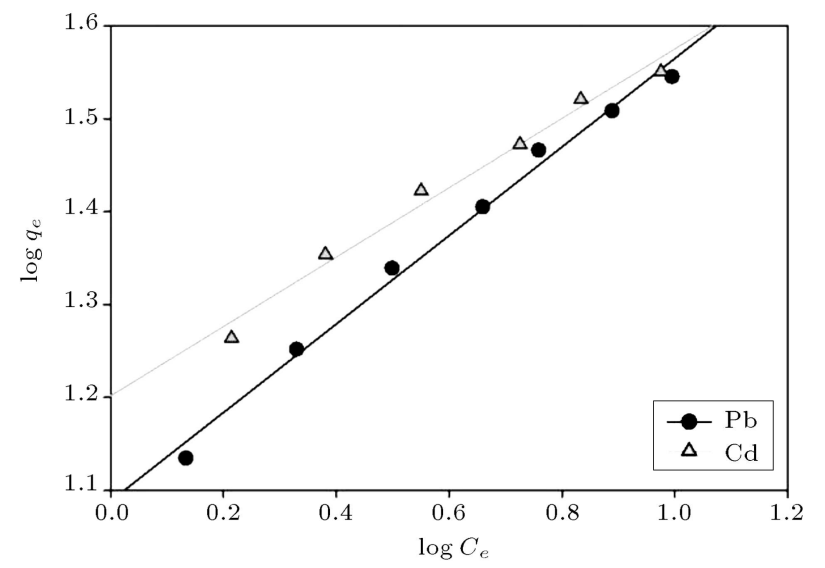

Figure 13. Freundlich isotherms for $\mathrm{Pb}(\mathrm{II})$ and $\mathrm{Cd}(\mathrm{II})$ adsorption $(\mathrm{pH}=6$, time $=90 \mathrm{~min}$, resin dose $=1 \mathrm{~g} / \mathrm{L})$.

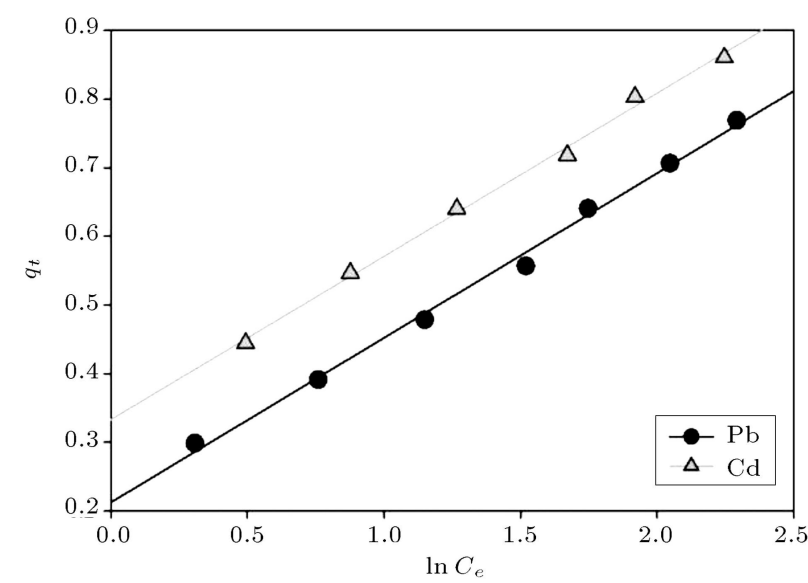

Figure 14. Temkin isotherms for adsorption of $\mathrm{Pb}(\mathrm{II})$ and $\mathrm{Cd}(\mathrm{II})(\mathrm{pH}=6$, time $=90 \mathrm{~min}$, resin dose $=1 \mathrm{~g} / \mathrm{L})$. and $(\mathrm{C})$.

of $K_{F}$ and $n$ for $\mathrm{Pb}^{2+}$ and $\mathrm{Cd}^{2+}$ ions are presented in Table 2. As seen in the previous section, the Langmuir isotherm model has been observed to be a better fit compared to Freundlich isotherm.

\subsubsection{Temkin isotherm}

The Temkin model was selected for obtaining related interaction parameters between adsorbent and metal ions. The linear form can be expressed as Eq. (10):

$$
q_{e}=B_{T} \ln A_{T}+B_{T} \ln C_{e},
$$

where $B_{T}$ is the difference between adsorption energies $(\mathrm{kJ} / \mathrm{mol})$ and $A_{T}$ is Temkin constant $(\mathrm{L} / \mathrm{g})$, which is related to the maximum energy [28]. The Temkin model was applied on experimental data the result of which are presented in Figure 14; also the slope and ordinate of obtained lines are presented in Table 2. These results showed that the value of $A_{T}$ for $\mathrm{Cd}^{2+}$ was higher than $\mathrm{Pb}^{2+}$, which was attributed to the effect of the ion exchange process during polymer-metal interactions, which was higher for $\mathrm{Cd}^{2+}$ compared with $\mathrm{Pb}^{2+}$. 


\subsubsection{Dubinin and Radushkevich isotherm}

The Dubinin and Radushkevich model for approximation adsorption free energy $(E)$ for heavy metal ions adsorption was studied. The supporting linear equation for this model can be expressed as Eq. (11) [29]:

$$
\ln C_{a d s}=\ln X_{m}-\beta s^{2},
$$

where $C_{a d s}, X_{m}, \beta$, and $S$ are the number of heavy metal ions adsorbed in the mass unit of polymer $(\mathrm{mol} / \mathrm{g})$, maximum adsorption capacity $(\mathrm{mol} / \mathrm{g})$, constant of adsorption energy $\left(\mathrm{mol}^{2} / \mathrm{kJ}^{2}\right)$, and Polanyi potential, respectively. The parameter of $S$ of the above equation can be obtained from Eq. (12):

$$
S=R T \ln \left(1+\frac{1}{C_{e}}\right)
$$

where $R$ is the global constant of gasses $(\mathrm{kJ} / \mathrm{mol})$ and $T$ is the absolute temperature. Using the slope and the ordinate of the curve, $\ln C_{a d s}$ versus $S^{2}, \beta$, and $X_{m}$ can be, respectively, obtained. The experimental results are indicated in Figure 15.

The obtained straight lines were useful for calculating the Dubinin isotherm constants, which are given in Table 2. The adsorption energy can also be calculated using Eq. (13):

$$
E=\frac{1}{\sqrt{-2 \beta}} \text {. }
$$

The free energy for the adsorption of $\mathrm{Pb}^{2+}$ and $\mathrm{Cd}^{2+}$ was $1.58 \mathrm{~kJ} / \mathrm{mol}$ and $2.24 \mathrm{~kJ} / \mathrm{mol}$, respectively, and these values are lower than $8 \mathrm{~kJ} / \mathrm{mol}$. This implies that the findings of the present study approve the physical adsorption property of the synthesized polymer under consideration.

\subsection{Kinetic study of new adsorbent}

It was found that the adsorption process could be

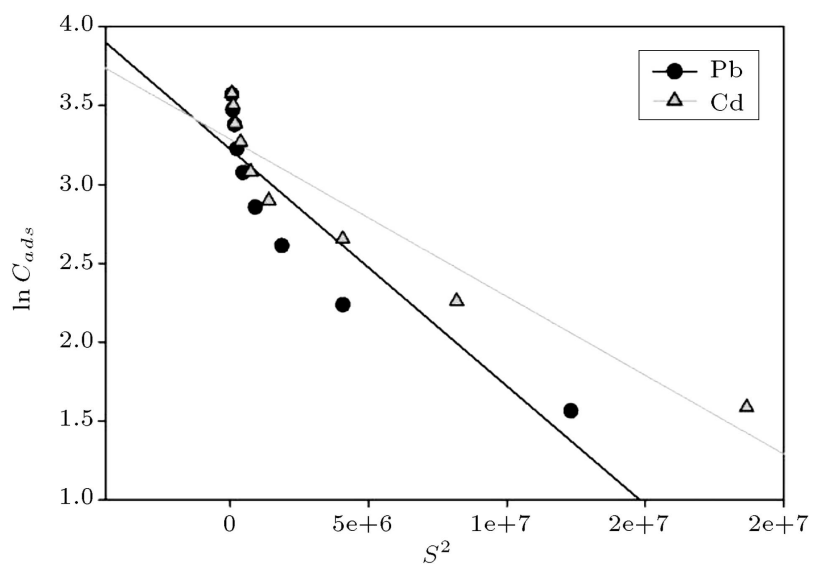

Figure 15. Dubinin-Radushkevich isotherms for adsorption of $\mathrm{Pb}(\mathrm{II})$ and $\mathrm{Cd}(\mathrm{II})(\mathrm{pH}=6$, time $=90 \mathrm{~min}$, resin dose $=1 \mathrm{~g} / \mathrm{L})$. effective for the removal of different contaminants from aqueous solutions. The kinetic predictions of closed equilibriums are considered for designing the adsorption systems.

\subsubsection{Pseudo-first order model}

The model of pseudo-first-order equation for investigating the kinetic characteristics of heavy metal ions adsorption was selected. The linear form of this model can be expressed as Eq. (14) [30]:

$$
\log \left(q_{e}-q_{t}\right)-\frac{K_{1}}{2.303} t
$$

where $q_{e}$ is the adsorbed metal ions in the equilibrium state $(\mathrm{mg} / \mathrm{g}), q_{t}$ is the adsorbed metal ions in time $t$, and $K_{1}$ is the rate constant for pseudo-first-order equation $(1 / \mathrm{min})$. The slope of the curve, log $\left(q_{e^{-}}\right.$ $\left.q_{t}\right)$, against $t$ is shown in Figure 16. The values of $K_{1}$ parameters for target ions were obtained and are presented in Table 3 . The values of $R^{2}$ were relatively low and the calculated $q_{e}$ was in good agreement with the experimental values.

\subsubsection{Pseudo-second order model}

Ho and McKay proposed a second-order equation for adsorption systems containing bivalent metal ions [31], which is based on the amount of the adsorbed material by adsorbent. The linear form of this equation can be expressed as Eq. (15):

$$
\frac{1}{q_{t}}=\frac{1}{K_{2} q_{e}^{2}}+\frac{1}{q_{e}} t,
$$

in which $K_{2}$ is the second-order rate constant and $q_{t}$ is the amount of the metal ions adsorbed in the time $t$. The kinetic constants of the pseudo-second-order equation $\left(K_{2}\right.$ and $\left.q_{e}\right)$ are plotted in the curves $t / q_{t}$ versus $t$ (Figure 17). The kinetic investigations relating to the adsorption of $\mathrm{Pb}^{2+}$ and $\mathrm{Cd}^{2+}$ from aqueous

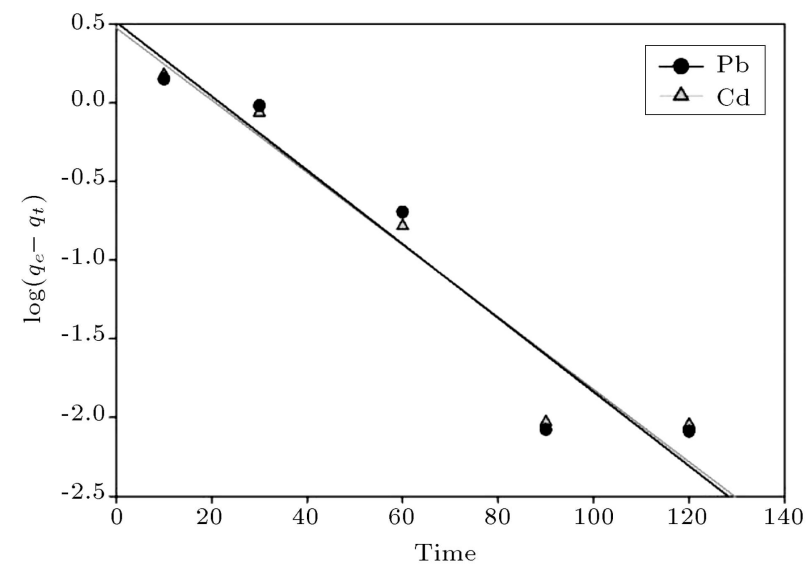

Figure 16. Pseudo-first-order plot for $\mathrm{Pb}(\mathrm{II})$ and $\mathrm{Cd}(\mathrm{II})$ adsorption $(\mathrm{pH}=6$, concentration of metal ions $=10$ $\mathrm{mg} / \mathrm{L}$, resin dose $=1 \mathrm{~g} / \mathrm{L})$. 
Table 3. Kinetic parameters for the adsorption of $\mathrm{Pb}^{2+}$ and $\mathrm{Cd}^{2+}$ ion onto the polymer.

\begin{tabular}{|c|c|c|c|}
\hline \multirow[b]{2}{*}{ Kinetic models } & \multirow[b]{2}{*}{ Parameters } & \multicolumn{2}{|c|}{ Metal ions } \\
\hline & & $\mathrm{Pb}^{+2}$ & $\mathrm{Cd}^{+2}$ \\
\hline \multirow[t]{5}{*}{ Pseudo-first order model } & $q_{e, \exp }(\mathrm{mg} / \mathrm{g})$ & 4.821 & 4.852 \\
\hline & $q_{e, c a l}(\mathrm{mg} / \mathrm{g})$ & 3.255 & 3.003 \\
\hline & $K_{1}(1 / \min )$ & 0.0541 & 0.0530 \\
\hline & $R^{2}$ & 0.9234 & 0.9352 \\
\hline & S.D. $(\%)$ & 32.475 & 38.102 \\
\hline \multirow[t]{5}{*}{ Pseudo-second order model } & $q_{e, \exp }(\mathrm{mg} / \mathrm{g})$ & 4.821 & 4.852 \\
\hline & $q_{e, c a l}(\mathrm{mg} / \mathrm{g})$ & 5.089 & 5.097 \\
\hline & $K_{2}(\mathrm{~g} / \mathrm{mg} \min )$ & 0.0267 & 0.0298 \\
\hline & $R^{2}$ & 0.9986 & 0.9992 \\
\hline & S.D. $(\%)$ & 5.5602 & 5.0462 \\
\hline \multirow[t]{6}{*}{ Intra-particle diffusion model } & $K_{p 1}\left(\mathrm{mg} / \mathrm{g} \min ^{1 / 2}\right)$ & 0.2636 & 0.297 \\
\hline & $K_{p 2}\left(\mathrm{mg} / \mathrm{g} \min ^{1 / 2}\right)$ & 0.0408 & 0.0328 \\
\hline & $C_{1}$ & 2.4905 & 2.3894 \\
\hline & $C_{2}$ & 4.3519 & 4.4725 \\
\hline & $\left(R_{1}\right)^{2}$ & 0.9732 & 0.9977 \\
\hline & $\left(R_{2}\right)^{2}$ & 0.6619 & 0.6634 \\
\hline
\end{tabular}

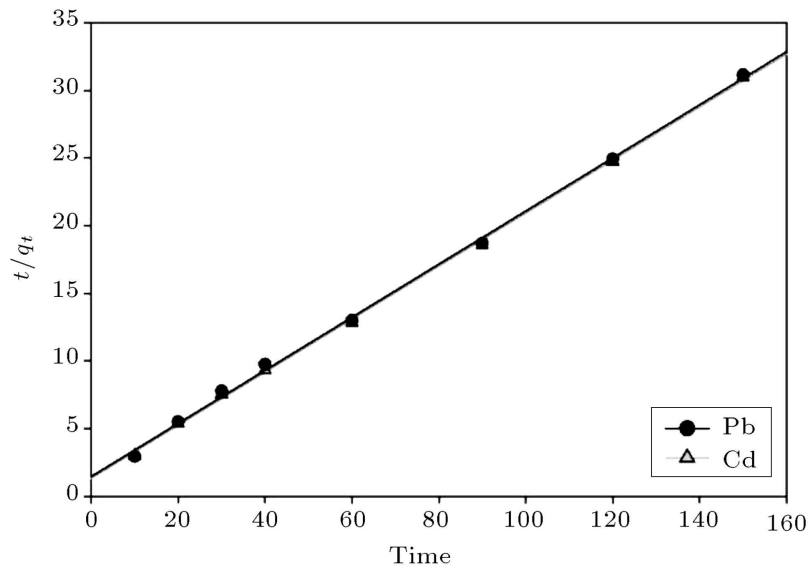

Figure 17. Pseudo-second-order plot for $\mathrm{Pb}(\mathrm{II})$ and $\mathrm{Cd}(\mathrm{II})$ adsorption $(\mathrm{pH}=6$, concentration of metal ions $=$ $10 \mathrm{mg} / \mathrm{L}$, resin dose $=1 \mathrm{~g} / \mathrm{L})$.

solutions were in fair agreement with pseudo-secondorder equations proposed by Ho [31] (Table 3).

The high amounts of $R^{2}$ and their good agreement with $q_{e}$ and related experimental data confirmed a mechanism of adsorption in which the adsorbent polymer follows the pseudo-second-order.

3.6.3. Investigation of intra-particle diffusion kinetic Developed by Weber and Morris, this model is often used to investigate the determining step in the adsorption process (Eq. (16)) [32]:

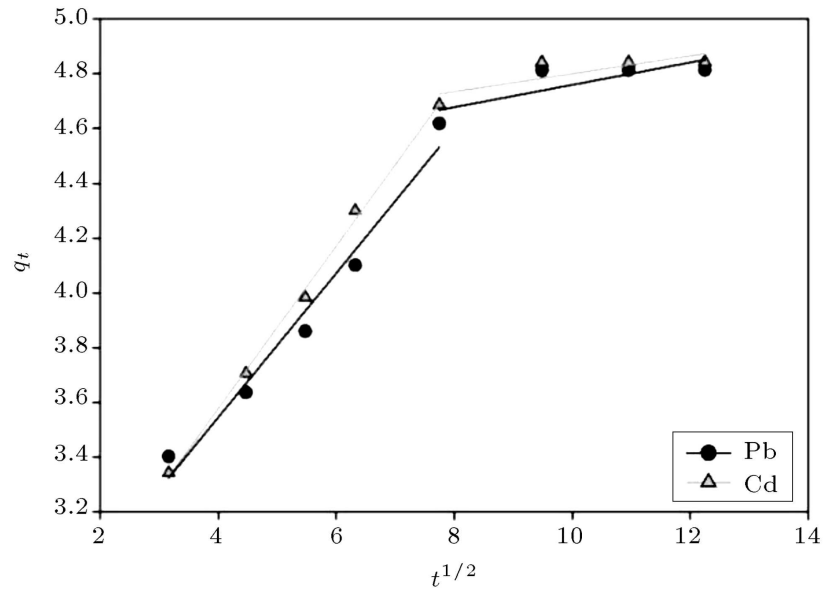

Figure 18. Intra-particle diffusion plot for $\mathrm{Pb}(\mathrm{II})$ and $\mathrm{Cd}(\mathrm{II})$ adsorption $(\mathrm{pH}=6$, concentration of metal ions $=$ $10 \mathrm{mg} / \mathrm{L}$, resin dose $=1 \mathrm{~g} / \mathrm{L})$.

$$
q_{t}=k_{p i} t^{1 / 2}+C_{i}
$$

where $k_{p i}$ is intra-particle diffusion constant $(\mathrm{mg} / \mathrm{g}$ $\min ^{1 / 2}$ ) and $C_{i}$ is another constant for the thickness of the barrier layer $(\mathrm{mg} / \mathrm{g})$. They can be obtained, respectively, from the slope and ordinate of the curve $q_{t}$ versus $t^{1 / 2}$; the obtained results are shown in Figure 18.

As can be seen, this curve is multi-lines for $\mathrm{Pb}^{2+}$ and $\mathrm{Cd}^{2+}$, indicating that the adsorption process is governed by more than one step. Based on these curves, the adsorption process of these two metal ions includes 
two steps. Therefore, the intra-particle kinetic model should not be taken as the unique and determining step during the reaction [33]. The first sharp portion of the curve shows the diffusion of metal ions onto the internal surface of adsorbent (liquid film diffusion). The second portion of the curve is responsible for the diffusion of metal ions into the pores of adsorbent (intra-particle diffusion). This portion of the curve express the slowest and determining step of the reaction [34]. The obtained results are listed in Table 3 . Based on these results, for both metal ions, $K_{p 1}$ was higher than $K_{p 2}$, indicating that the concentration of metal ions decreased rapidly.

\subsubsection{The validity of kinetic models}

To find the best model for describing the mechanism of $\mathrm{Pb}^{2+}$ and $\mathrm{Cd}^{2+}$ adsorption onto the surface of the synthesized polymer, the percent of normal standard deviation ( $S D \%$ ) was considered by using Eq. (17) [35]:

$$
S D(\%)=100 \times\left\{\sum \frac{\left[\left(q_{e, \exp }-q_{e, c a l}\right) / q_{e, \exp }\right]^{2}}{N-1}\right\}^{1 / 2},
$$

where $q_{e, \exp }$ is the equilibrium adsorption capacity $(\mathrm{mg} / \mathrm{g}), q_{e, c a l}$ is the calculated adsorption capacity (mg/g), and $N$ is the points of data. Based on the results of Table 3, the obtained values of $S D$ for the pseudo-first-order kinetic model were higher than those obtained for the pseudo-second-order model. Furthermore, the higher values for $R^{2}$ in the pseudo-secondorder model indicated that this model was the most appropriate equation for describing the adsorption kinetics of $\mathrm{Pb}^{2+}$ and $\mathrm{Cd}^{2+}$ using synthesized polymer. Consequently, the total rate of adsorption process was controlled by chemical adsorption, including covalent forces originated from sharing or exchange electrons between the adsorbent and the adsorbed material [36].

\subsection{Thermodynamic adsorption study}

The free energy and enthalpy are the important factors, which should be determined during an adsorption process and any other unexpected event. These parameters are the actual criterion for adsorption processes. The adsorption capacity depends on these thermodynamic parameters. The calculation of the adsorption thermodynamics using Wanthof method can be performed by Eqs. (18)-(20):

$$
\begin{aligned}
& K_{c}=\frac{C_{A}}{C_{S}}, \\
& \Delta G^{0}=-R T \ln K_{c}, \\
& \ln K_{c}=\frac{\Delta S^{0}}{R}-\frac{\Delta H^{0}}{R}\left(\frac{1}{T}\right),
\end{aligned}
$$

where $K_{c}$ is equilibrium constant, $C_{A}$ is the concentration of the adsorbed metal ions onto the surface of adsorbent at equilibrium state $(\mathrm{mol} / \mathrm{L}), C_{s}$ is the concentration of metal ions in the solution at equilibrium state $(\mathrm{mol} / \mathrm{L})$, and $\Delta G^{\prime}$ is the representative of the standard free energy $(\mathrm{kJ} / \mathrm{mol}) . \Delta S^{\prime \prime}$ and $\Delta H^{\prime \prime}$ are, respectively, the standard entropy $(\mathrm{kJ} / \mathrm{mol})$ and enthalpy $(\mathrm{kJ} / \mathrm{mol})$ [37]. The calculation of the related parameters required that the slope and the ordinate values of the Vant hoof graph to be plotted, thus the $\ln K_{c}$ versus $1 / T$ was plotted the results of which are shown in Figure 19.

The increase of the values of $T$ may lead to the decrease of the values of $K[38,39]$. The calculated values for these thermodynamical parameters are given in Table 4. The positive numbers of $\Delta H$ proved that the adsorption process was endothermic and that the strong bonds between metal ions and adsorbent was probable. Also, the results showed that the adsorption process was temperature-sensitive.

The positive values of entropy indicated the tendency of adsorbent to adsorb the materials and some structural variations of these adsorbent. These values could be considered as the confirmative evidences approving the ascending trend of the reaction. There was a converse relation between $\Delta G^{\prime \prime}$ and temperature and the increase of the temperature caused the reaction

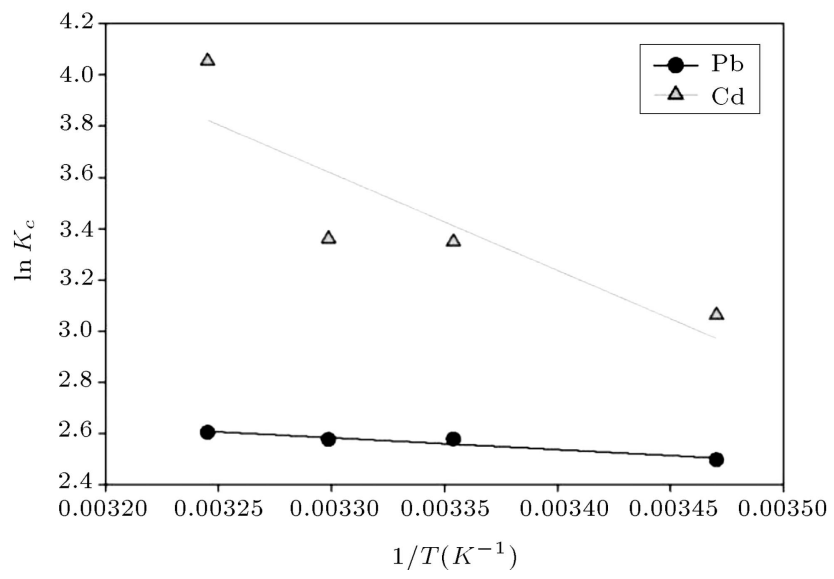

Figure 19. The plot of $\log K_{c}$ against $1 / T$ for adsorbing $\mathrm{Pb}(\mathrm{II})$ and $\mathrm{Cd}(\mathrm{II})$ metal ions onto the polymer.

Table 4. Thermodynamic data for $\mathrm{Pb}^{2+}$ and $\mathrm{Cd}^{2+}$ adsorption onto the polymer.

\begin{tabular}{cccc}
\hline & & \multicolumn{2}{c}{ Metal ions } \\
\cline { 3 - 4 } Parameters & Temperature & $\mathbf{P b}^{+\mathbf{2}}$ & $\mathbf{C d}^{+\mathbf{2}}$ \\
\hline$\Delta G_{0}(\mathrm{~kJ} / \mathrm{mol})$ & 288.15 & -5.9828 & -7.3376 \\
& 298.15 & -6.3906 & -8.3016 \\
& 303.15 & -6.4940 & -8.4711 \\
& 308.15 & -6.6726 & -10.3861 \\
$\Delta H_{0}(\mathrm{~kJ} / \mathrm{mol})$ & & & \\
$\Delta S_{0}(\mathrm{~kJ} / \mathrm{mol} . \mathrm{K})$ & & +3.8338 & +31.4718 \\
\hline
\end{tabular}


to show a clear tendency towards the spontaneous performance.

\section{Conclusion}

A new synthesized polymer adsorbent was introduced and its capability for adsorbing the heavy metal ions was investigated. The capability of the synthesized polymer for adsorbing the $\mathrm{Pb}^{2+}$ and $\mathrm{Cd}^{2+}$ was approved and it was revealed that it could be used as an efficient adsorbent for adsorbing the heavy metal ions in the $\mathrm{pH}$ range of $2-6$. By increasing the adsorbent dose from 0.5 to $3.0 \mathrm{~g} / \mathrm{L}$, the removal percentage of the heavy metal ions increased. The adsorption percentage of heavy metal ions increases with increasing the test time to $60-80$ minutes and after this time the adsorption percentage remains constant. The Langmuir, Freundlich, Temkin, and Dubinin-Radushkevich isotherms equilibrium data have been applied to the experimental data and the characteristic parameters for each isotherm and related correlation coefficients were determined. The excellent fits were observed within the following isotherms order which is based on their correlation coefficient values: Langmuir > Freundlich $>$ Temkin $>$ Dubinin-Radushkevich. The adsorption energy from the Dubinin-Radushkevich isotherm was found at 1.58 and $2.24 \mathrm{~kJ} / \mathrm{mol}$ for $\mathrm{Pb}^{2+}$ and $\mathrm{Cd}^{2+}$, respectively. For investigating the adsorption mechanism, the following three simplified kinetic models including pseudo-first-order, pseudosecond-order, and intra-particle diffusion were tested. The results showed that considering the highest $R^{2}$ values, the pseudo-second-order kinetic model showed the best fit with the dynamic adsorption behavior of $\mathrm{Pb}^{2+}$ and $\mathrm{Cd}^{2+}$ ions. The findings showed that the HEMA-AA-BDDMA polymer as a reusable polymer has a good potential for adsorbing the metal ions up to 15 cycles while still maintaining its efficiency and performance quality. Due to its high efficiency, this polymer could be used for removing the toxic metal ions. This is a simple, green, and clean technology and it could provide an strategic solution for removing heavy metals from industrial sewage and waste. It can also be used for separating $\mathrm{Pb}^{2+}$ and $\mathrm{Cd}^{2+}$ ions in the separation columns because of its high adsorption and desorption efficiency.

\section{References}

1. Moore, J.W., Inorganic Contaminants of Surface Water, Research and Monitoring Priorities, Springer Science \& Business Media (2012).

2. Rao, K., Mohapatra, M., Anand, S., et al. "Review on cadmium removal from aqueous solutions", Int. J. Eng. SCI. Tech., 2(7), pp. 81-103 (2010).
3. Naiya, T.K. and Bhattacharya, A.K., Das, S.K. "Adsorption of $\mathrm{Cd}$ (II) and $\mathrm{Pb}$ (II) from aqueous solutions on activated alumina", J. Colloid Interf. Sci., 333(1), pp. 14-26 (2009).

4. Ceglowski, M., Gierczyk, B., Frankowski, M., et al. "A new low-cost polymeric adsorbents with polyamine chelating groups for efficient removal of heavy metal ions from water solutions", React. Funct. Polym., 131, pp. 64-74 (2018).

5. Ramrakhiani, L., Ghosh, S., and Majumdar, S. "Surface modification of naturally available biomass for enhancement of heavy metal removal efficiency, upscaling prospects, and management aspects of spent biosorbents: a review", Appl. Biochem. Biotechnol., 180(1), pp. 41-78 (2016).

6. Ahmad, M., Manzoor, K., Ahmad, S., et al. "Preparation, kinetics, thermodynamics, and mechanism evaluation of thiosemicarbazide modified green carboxymethyl cellulose as an efficient $\mathrm{Cu}(\mathrm{II})$ adsorbent", J. Chem. Eng. Data., 63(6), pp. 1905-1916 (2018).

7. Ahmsad, M., Manzoor, K., Chaudhuri, R.R., et al. "Thiocarbohydrazide cross-linked oxidized Chitosan and Poly(vinyl alcohol): A green framework as efficient $\mathrm{Cu}(\mathrm{II}), \mathrm{Pb}(\mathrm{II})$, and $\mathrm{Hg}$ (II) adsorbent", J. Chem. Eng. Data, 62(7), pp. 2044-2055 (2017).

8. Ahmad, M., Manzoor, K., and Ikram, S. "Versatile nature of hetero-chitosan based derivatives as biodegradable adsorbent for heavy metal ions, a review", Int. $J$. Biol. Macromolecules, 105, pp. 190-203 (2017).

9. Ahmad, M., Manzoor, K., Venkatachalam, P., et al. "Kinetic and thermodynamic evaluation of adsorption of $\mathrm{Cu}$ (II) by thiosemicarbazide chitosan", Int. J. Biol. Macromolecules, 92, pp. 910-919 (2016).

10. Carolin, C.F., Kumar, P.S., Saravanan, A., et al. "Efficient techniques for the removal of toxic heavy metals from aquatic environment: a review", J. Environ. Chem. Eng., 5(3), pp. 2782-2799 (2017).

11. Selvi, A., Rajasekar, A., Theerthagiri, J., et al. "Integrated remediation processes toward heavy metal removal/recovery from various environments: a review", Fron. Environ. Sci., 7(66), p. 2 (2019).

12. Barakat, M.A. "New trends in removing heavy metals from industrial wastewater", Arab. J. Chem., 4(4), pp. 361-377 (2011).

13. Muhammad Ekramul Mahmud, H.N., Huq, A.K.O., and Yahya, R.B. "The removal of heavy metal ions from wastewater/aqueous solution using polypyrrolebased adsorbents: a review", $R S C A d v$., 6(18), pp. 14778-14791 (2016).

14. Li, N., Wei, X., Mei, Z., et al. "Synthesis and characterization of a novel polyamidoamine-cyclodextrin crosslinked copolymer", Carbohyd. Res., 346(13), pp. 1721-1727 (2011).

15. Alsohaimi, I.H., Wabaidur, S.M., Kumar, M., et al. "Synthesis, characterization of PMDA/TMSPEDA 
hybrid nanocomposite and its applications as an adsorbent for the removal of bivalent heavy metals ions", Chem. Eng. J., 270, pp. 9-21 (2015).

16. Zhou, G., Luo, J., Liu, C., et al. "A highly efficient polyampholyte hydrogel sorbent based fixed-bed process for heavy metal removal in actual industrial effluent", Water Res., 89, pp. 151-160 (2016).

17. Jafari, S., Dehghani, M., Nasirizadeh, N., et al. "Synthesis and characterisation of a selective adsorbent based on the molecularly imprinted polymer for the removal of cloxacillin antibiotic residue from milk", Int. J. Dairy. Technol., 70, pp. 1-10 (2019).

18. Jafari, S., Dehghani, M., Nasirizadeh, N., et al. "Labelfree electrochemical detection of cloxacillin antibiotic in milk samples based on molecularly imprinted polymer and graphene oxide-gold nanocomposite", Measurement, 145, pp. 22-29 (2019).

19. Chen, C.Y. and Chen, C.Y. "Stability constants of polymer-bound iminodiacetate-type chelating agents with some transition-metal ions", J. Appl. Polym. Sci., 86(8), pp. 1986-1994 (2002).

20. Wang, L., Yang, L., Li, Y., et al. "Study on adsorption mechanism of $\mathrm{Pb}$ (II) and $\mathrm{Cu}$ (II) in aqueous solution using PS-EDTA resin", Chem. Eng. J., 163(3), pp. 364-372 (2010).

21. Chen, C.Y. and Chen, S.Y. "Adsorption properties of a chelating resin containing hydroxy group and iminodiacetic acid for copper ions", J. Appl. Polym. Sci., 94(5), pp. 2123-2130 (2004).

22. Das, N. "Remediation of radionuclide pollutants through biosorption - an overview", Clean-Soil Air Water, 40(1), pp. 16-23 (2012).

23. Chen, C.-Y. and Chen, C.-Y. "Stability constants of water-soluble and latex types of chelating polymers containing iminodiacetic acid with some transitionmetal ions", Eur. Polym. J., 39(5), pp. 991-1000 (2003).

24. Langmuir, I. "The adsorption of gases on plane surfaces of glass, mica and platinum", J. Am. Chem. soc., 40(9), pp. 1361-1403 (1918).

25. Freundlich, H. "Über die adsorption in lösungen", $Z$. Phys. Chem., 57(1), pp. 385-470 (1907).

26. Temkin, M. and Pyzhev, V. "Recent modifications to Langmuir isotherms", Acta Physico-Chimica Sinica, 12, pp. 217-222 (1940).

27. Dubinin, M. "Modern state of the theory of volume filling of micropore adsorbents during adsorption of gases and steams on carbon adsorbents", Zh. Fiz. Khim +, 39(19), pp. 1305-1317 (1965).

28. Yousef, R.I., El-Eswed, B., and Ala'a, H. "Adsorption characteristics of natural zeolites as solid adsorbents for phenol removal from aqueous solutions: kinetics, mechanism, and thermodynamics studies", Chem. Eng. J., 171(3), pp. 1143-1149 (2011).

29. Yusan, S., Gok, C., Erenturk, S., et al. "Adsorptive removal of thorium (IV) using calcined and flux calcined diatomite from Turkey: evaluation of equilibrium, kinetic and thermodynamic data", Appl. Clay. Sci., 67, pp. 106-116 (2012).

30. Ghasemi, Z., Seif, A., Ahmadi, T.S., et al. "Thermodynamic and kinetic studies for the adsorption of $\mathrm{Hg}$ (II) by nano-TiO2 from aqueous solution", Adv. Powder Technol., 23(2), pp. 148-156 (2012).

31. Ho, Y.-S. "Second-order kinetic model for the sorption of cadmium onto tree fern: a comparison of linear and non-linear methods", Water Research, 40(1), pp. 119125 (2006).

32. Weber, W.J. and Morris, J.C. "Kinetics of adsorption on carbon from solution", J. Sanit. Eng. Div., 89(2), pp. 31-60 (1963).

33. Ho, Y.-S. and Ofomaja, A.E. "Kinetics and thermodynamics of lead ion sorption on palm kernel fibre from aqueous solution", Process Biochem., 40(11), pp. 3455-3461 (2005).

34. Figaro, S., Avril, J., Brouers, F., et al. "Adsorption studies of molasse's wastewaters on activated carbon: Modelling with a new fractal kinetic equation and evaluation of kinetic models", J. Hazard. Mater., 161(23), pp. 649-656 (2009).

35. Cheng, B., Le, Y., Cai, W., et al. "Synthesis of hierarchical $\mathrm{Ni}(\mathrm{OH}) 2$ and $\mathrm{NiO}$ nanosheets and their adsorption kinetics and isotherms to Congo red in water", J. Hazard. Mater., 185(2-3), pp. 889-897 (2011).

36. Hameed, B., Tan, I., and Ahmad, A. "Adsorption isotherm, kinetic modeling and mechanism of $2,4,6$ trichlorophenol on coconut husk-based activated carbon", Chem. Eng. J., 144(2), pp. 235-244 (2008).

37. Siahkamari, M., Jamali, A., Sabzevari, A., et al. "Removal of lead (II) ions from aqueous solutions using biocompatible polymeric nano-adsorbents: A comparative study", Carbohyd. Polym., 157, pp. 11801189 (2017).

38. Özcan, A., Öncü, E.M., and Özcan, A.S. "Kinetics, isotherm and thermodynamic studies of adsorption of acid blue 193 from aqueous solutions onto natural sepiolite", Colloid Surface A., 277(1-3), pp. 90-97 (2006).

39. Liu, Y., Hu, L., Yao, Y., et al. "Construction of composite chitosan-glucose hydrogel for adsorption of Co2+ ions", Int. J. Biol. Macromol., 139, pp. 213-220 (2019).

\section{Biographies}

Reza Abdolahi studied for a bachelor's degree in applied chemistry at Urmia University during 20122016. After completing the undergraduate course, he was studying for a master's degree at Urmia University for two years, when he finally received his degree in Analytical Chemistry in 2018. During these two years, he studied the synthesis of some polymeric 
adsorbents and their effect on the removal of heavy metals from water. In his recent work, he synthesized a novel polymeric adsorbent based on 2-hydroxyethyl methacrylate and tested its efficiency in the removal of $\mathrm{Pb}^{2+}$ and $\mathrm{Cd}^{2+}$.

Vahabodin Goodarzi is affiliated to the Applied Biotechnology Research Center, Baqiyatallah University of Medical Sciences, Iran. Currently, he is working on application of various biomaterials and nanocomposites in tissue engineering field. His many research studies have been focused on synthesis a new bio-polyester and copolymerization such poly(glycerol-sebacic acid) (PGS), poly(glycerolazelaic acid) (PGAZ), poly(glycerol-succinic acid)
(PGSU), Poly(xylitol-dodecanedioic acid), PGS-coPLA, PGS-co-PCL, and their families. In the meantime, he has published very interesting articles in high quality journals.

Mohammad Hadi Baghersad is an Assistant Professor at the Applied Biotechnology Research Center, Baqiyatallah University of Medical Sciences. He researched the synthesis of novel organic compounds and polymers. Still, the applicable and useful ones are further in his interest, such as molecularly imprinted and ion absorbent polymers, biodegradable and compatible polymers, polymer grafted-nanoparticles, and organic molecules such as pharmaceuticals, potentially drugs, plasticizers and so on. 